\title{
Reduced chemistry for butanol isomers at engine-relevant conditions
}

\author{
Xin Hui, ${ }^{* \dagger \dagger}$ Kyle E. Niemeyer, ${ }^{\ddagger}$ Kyle B. Brady,,$~ §$ and Chih-Jen Sung \\ $\dagger$ School of Energy and Power Engineering, Beihang University, Beijing, China \\ †School of Mechanical, Industrial, and Manufacturing Engineering, Oregon State \\ University, Corvallis, OR, USA \\ \Department of Mechanical Engineering, University of Connecticut, Storrs, CT, USA \\ §Innovative Scientific Solutions Inc., Dayton, OH, USA \\ E-mail: huixin@buaa.edu.cn
}

\begin{abstract}
Butanol has received significant research attention as the second-generation biofuel in the past few years. In the present study, skeletal mechanisms for four butanol isomers were generated from two widely accepted, well-validated detailed chemical kinetic models for the butanol isomers. The detailed models were reduced using a two-stage approach consisting of the directed relation graph with error propagation and sensitivity analysis. During the reduction process, issues encountered with pressure-dependent reactions formulated using the logarithmic pressure interpolation approach were discussed, with recommendations made to avoid ambiguity in its future implementation in mechanism development. The performances of the skeletal mechanisms generated here were compared with those of detailed mechanisms in simulations of autoignition delay times, laminar flame speeds, and perfectly stirred reactor temperature response curves and extinction residence times, over a wide range of pressures, temperatures,
\end{abstract}


and equivalence ratios. Good agreement was observed between the detailed and skeletal mechanisms, demonstrating the adequacy of the resulting reduced chemistry for all the butanol isomers in predicting global combustion phenomena. The skeletal mechanisms also closely predicted the time-histories of fuel mass fractions in homogeneous compression-ignition engine simulations. Finally, the performances of the butanol isomers were compared with that of a gasoline surrogate with an anti-knock index of 87 in a homogeneous compression-ignition engine simulation. The gasoline surrogate consumed faster than any of the butanol isomers, and tert-butanol had the slowest fuel consumption rate; $n$-butanol and isobutanol came closest to matching the gasoline, but the two literature chemical kinetic models predicted different orderings.

\section{Introduction}

Interest in renewable energy has grown significantly in the last decade, driven primarily by unstable oil prices and the environmental costs associated with fossil fuels. Alcohol biofuels, renewable fuels produced from biological sources, have attracted significant research interest because they may offer significant benefits in terms of reduced emissions, lowered lifecycle carbon footprint, improved price stability, and more distributed production facilities. Moreover, as a result of the reduced chemical complexity - relative to petroleum distillatesand the accompanying reduction in fuel variability associated with alcohol biofuels, detailed modeling of complete combustion systems becomes significantly more tractable, aiding the development of novel engine designs. However, while novel engine designs and alternative fuels promise improved efficiencies and better emissions performance, to a great extent their success depends on a comprehensive understanding of fuel kinetics. Robust chemical kinetic models are therefore needed that can provide accurate and efficient predictions of combustion performance across a wide range of engine relevant conditions. 


\section{Butanol}

Butanol has many advantages as a biofuel over ethanol, including a higher heating value, reduced corrosiveness and susceptibility to water contamination, better engine performance, and a wider range of feedstocks ${ }^{112}$. For these reasons, butanol is under consideration to replace ethanol as an alternative fuel to gasoline and diesel. Extensive efforts have been made in recent years to study the combustion performance of the four butanol isomers in various well-defined fundamental and engine experiments. Numerous fundamental studies have investigated a variety of combustion characteristics of the butanol isomers, including homogeneous autoignition delays ${ }^{3} \sqrt{7}$, counterflow ignition temperatures ${ }^{8}[10$, laminar flame

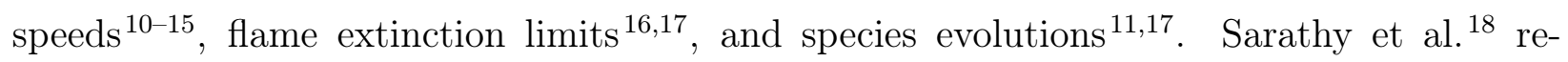
viewed fundamental experimental studies of alcohols, including the butanol isomers, and both Bergthorson and Thomson ${ }^{2}$ and $\mathrm{No}^{\sqrt{19}}$ reviewed the characteristics of butanol combustion in engines.

Several of these studies compared combustion properties among the four butanol isomers and found differences in ignition propensity ${ }^{5}-8$ and flame propagation ${ }^{13}[15$, demonstrating that the four isomers exhibit differing reactivities as a result of their different molecular structures, which Fig. 1 depicts. In addition, other studies focused on the combustion characteristics of $n$-butanol in terms of ignition temperature ${ }^{910}$, flame propagation $\underline{10}$, and speciation 11 . Lefkowitz et al. ${ }^{17}$ explored flame extinction and speciation to characterize the global reactivity of tert-butanol due to its distinctive characteristics compared with the other three butanol isomers. The performances of butanol blends with gasoline or diesel have also been assessed in spark ignition (SI) engines 20121 , compression ignition (CI) engines $22 \sqrt[24]{24}$, and advanced homogeneous charge compression ignition (HCCI) engines ${ }^{25 \mid 26}$ in terms of exhaust temperature, thermal efficiency, autoignition timing, and emissions. Aside from the work of Al-Hasan and Al-Momany ${ }^{22}$ on isobutanol, the majority of these studies focused on blends of $n$-butanol with conventional petroleum-derived fuels at various blending ratios. Recently, He et al. $\frac{27}{27}$ also evaluated the behavior of pure $n$-butanol in an HCCI engine in terms of 
combustion performance and emissions at engine speeds of 1200 and $1500 \mathrm{rpm}$.

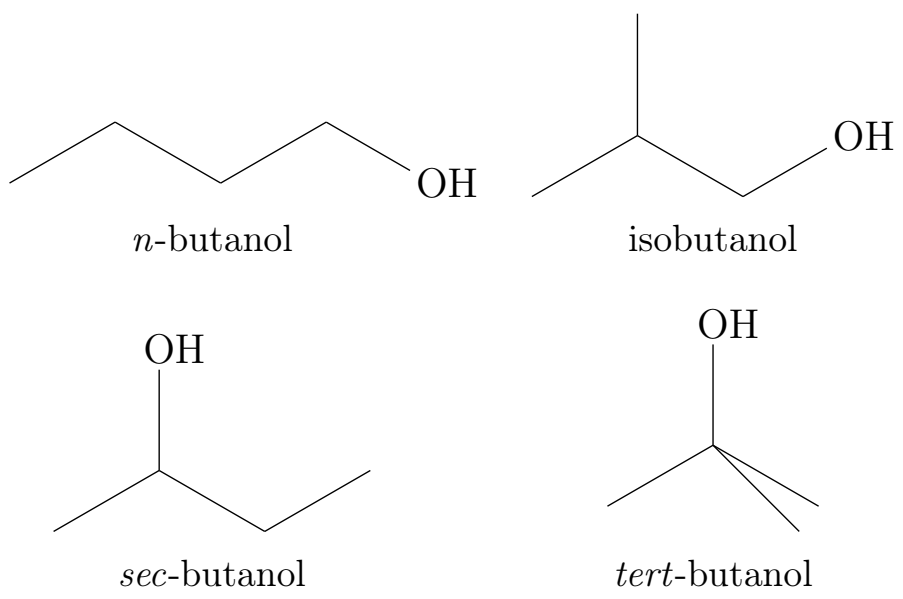

Figure 1: Molecular structure of butanol isomers

In addition to this experimental work, much progress has been made in developing kinetic models that describe the chemical kinetics of the butanol isomers; see Sarathy et al. 18 for a detailed review of these efforts. Moss et al. ${ }^{7}$ developed the first detailed chemical kinetic model for four butanol isomers based on the high temperature ignition delay data measured in a shock tube. Later, Dagaut et al. ${ }^{28}$ proposed a detailed chemical kinetic model for $n$-butanol based on jet stirred reactor data. Sarathy et al. $\frac{11}{11}$ then improved this model based on laminar flame speed and non-premixed flame speciation data, developing a detailed model for $n$-butanol consisting of 118 species and 878 reactions. More recently, Sarathy et al. ${ }^{29}$ proposed a detailed chemical kinetic model for $n$-, iso, sec-, and tert-butanols. The model describes low- and high-temperature oxidation of butanol isomers with 426 species and 2335 reactions, and Sarathy et al. ${ }^{[29}$ validated its performance with atmospheric pressure laminar flame speeds, low-pressure flame species profiles, intermediate-temperature shock tube ignition delay times for $n$-butanol, high-temperature shock tube ignition delay times for all four isomers, rapid-compression machine ignition delay times for all four isomers at low-to-intermediate temperatures, and jet-stirred reactor species profiles for selected isomers. Vasu and Sarathy ${ }^{\sqrt{30}}$ updated the model of Sarathy et al. ${ }^{29}$ in the high-temperature regime for $n$-butanol oxidation using rate constants measured in a single-pulse shock tube $\mathrm{e}^{31}$. The 
updated high-temperature model of Vasu and Sarathy ${ }^{30}$ consists of 284 species and 1892 reactions, and agrees better with experimental $n$-butanol data compared with the original model of Sarathy et al. 29 .

Frassoldati et al. $\stackrel{32}{32}$ also proposed a detailed chemical kinetic model for all four butanol isomers, with 317 species and 12,353 reactions. This model built on the work of Grana et al. $\frac{33}{33}$ and emphasizes the major decomposition and oxidation pathways of each respective butanol isomer in the high-temperature, low-pressure combustion regime. Frassoldati et al. 32 validated their detailed model using data from pyrolysis, shock-tube autoignition, and both premixed and non-premixed flame experiments.

Van Geem et al. ${ }^{34}$ proposed a detailed chemical kinetic model for $n$-, sec-, and tertbutanol, and validated it using shock-tube ignition delay times, pyrolysis data, and flame species profiles. Later, Merchant et al. $\frac{35}{35}$ studied the pyrolysis and combustion of isobutanol and added its chemical pathways to the model of Van Geem et al. 34 . The combined detailed model of Merchant et al. $\stackrel{35}{ }$ for all four butanol isomers consists of 372 species and 8723 reactions.

\section{Need for model reduction}

While the predictions of the aforementioned butanol models largely match fundamental experimental validation data, their large sizes pose a significant challenge to their implementation in practical engine simulations. The computational cost of detailed chemistry in such simulations scales cubically with the number of species (in the worst case) $\frac{36}{\text {. The re- }}$ sulting large number of governing differential equations for the set of species are nonlinearly coupled, and exhibit vastly different time scales that render them mathematically stiff $[36$. The large size and chemical stiffness of detailed chemical kinetic models therefore limit their application to large-scale simulations, and as such there is a growing need to reduce the size of these models while retaining their predictive capabilities.

A large number of model reduction methodologies have been developed in the past decade 
to counter the trend of increased numbers of species and reactions, as reviewed by Lu and Law ${ }^{36}$ and more recently by Turányi and Tomlin 3 . Among the various methods, the direct relation graph (DRG) approach of $\mathrm{Lu}$ and Law $\stackrel{38,41}{4}$ has received significant attention due to its effectiveness and efficiency. The DRG method built on the earlier approach of Bendtsen et al. $\stackrel{42}{6}$ for representing reaction pathways with weighted directed graphs, but instead uses the graph to quantify the importance of species. The weights of graph edges represent species interaction coefficients, which estimate the error induced in the overall production rate of one species by the removal of the other, and are determined with normalized contributions to the overall production rates. Low-valued graph edges then indicate unimportant relationships between species, and are trimmed; the DRG method produces a skeletal mechanism after trimming the graph in this way then identifying which species remain connected to certain important target species.

DRG is often used as the first step of a multistage reduction to quickly reduce a large detailed mechanism to a smaller skeletal mechanism. However, DRG only considers direct interactions between species and thus assumes the worst-case scenario for error propagation, and can generate non-minimal skeletal mechanisms. Pepiot-Desjardins and Pitsch ${ }^{43}$ proposed a more aggressive treatment that considers error propagation along the graph pathways: DRG with error propagation (DRGEP). The DRGEP method can generate smaller mechanisms compared with DRG alone $\mathrm{e}^{43[44}$, while maintaining the fidelity of the resulting skeletal mechanism to the original detailed description. Such skeletal mechanisms can be further reduced by various techniques such as sensitivity analysis (SA) ${ }^{446}$ and path flux analysis $\frac{47}{4}$. In addition, techniques based on time-scale analysis can be used to both effectively decrease mechanism size and reduce stiffness, such as invoking quasi-steady state approximations $^{48 / 49}$ and/or using computational singular perturbation methods 50 -533.

Given the potential application of butanol isomers in internal combustion engines, it is necessary to reduce butanol mechanism sizes for use in realistic engine simulations - without sacrificing chemical fidelity relative to the underlying detailed mechanism. Therefore, our 
first objective in this paper is to generate skeletal mechanisms for butanol isomers from available comprehensive models based on the DRGEPSA method, as described by Niemeyer et al. $\underline{44} \underline{465}$. We then compare intermediate and final skeletal mechanisms, resulting from the DRGEP and DRGEPSA (i.e., DRGEP followed by SA) methods, respectively, with their parent detailed mechanisms in terms of ignition delay times, laminar flame speeds, and perfectly stirred reactor (PSR) temperature response curves and extinction turning points, to assess the validity of the reduction methodology. In addition, we investigate the potential of replacing gasoline with butanol by comparing the engine performance of the butanol isomers and a gasoline surrogate. Finally, we discuss our overall conclusions and contributions of the paper.

\section{Methodology}

In this section, we describe the baseline chemical kinetic models, the reduction procedure, and validation of the resulting skeletal mechanisms. The reduction procedure used here is based on the approach of Niemeyer and coworkers 44 46|54, and a complete description can be found in those works. However, we provide an overview of the method here for completeness, and discuss a few notable changes.

\section{Chemical kinetic models}

We selected two detailed chemical kinetic models from the literature to generate skeletal mechanisms for the four butanol isomers: the mechanisms of Sarathy and coworkers 29130 and Merchant et al. ${ }^{35}$, hereafter referred to as the Sarathy mechanism (284 species, 1892 reactions) and Merchant mechanism (372 species, 8322 reactions), respectively. Note that

one reaction has been removed from the original Merchant mechanism due to an issue of negative rate coefficient in a pressure-dependent reaction, which will be further explained in due course. Both mechanisms include chemical pathways for all four butanol isomers: $n$-, 
iso, sec-, and tert-butanols. As discussed previously, Frassoldati et al.$^{32}$ developed another mechanism for all four butanol isomers. However, this model contains reactions with noninteger stoichiometric coefficients that make it incompatible with the current CHEMKINbased reduction code, and thus it is not included in the present study.

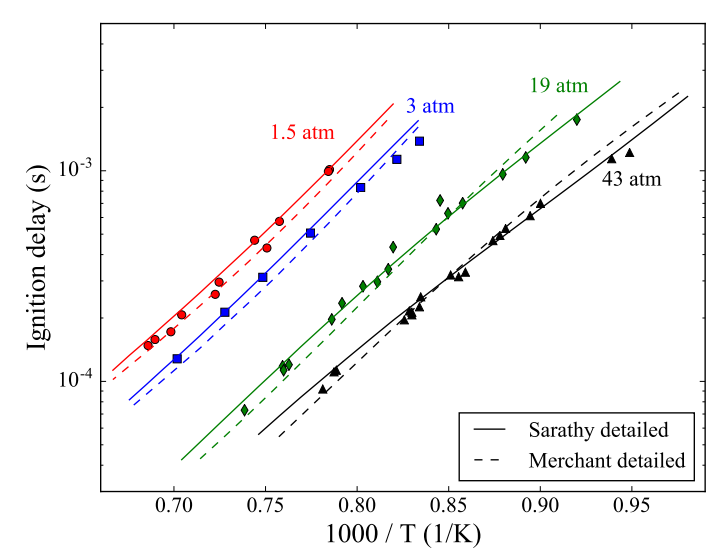

(a) $n$-butanol

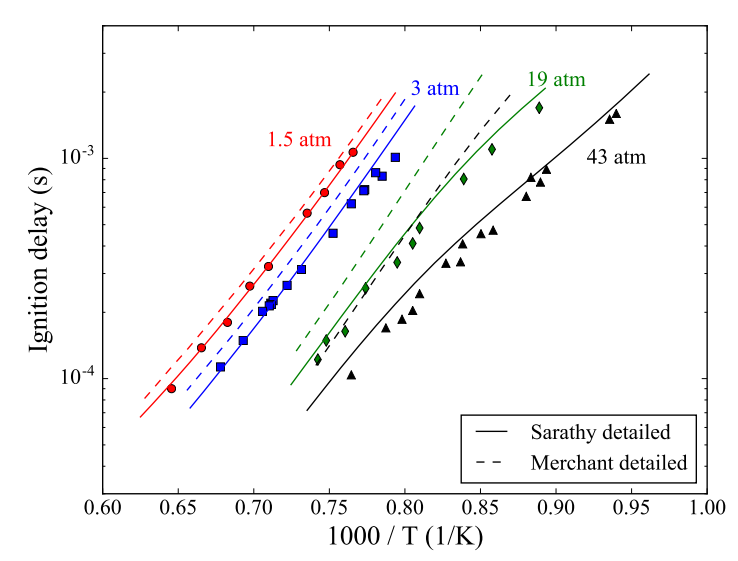

(c) sec-butanol

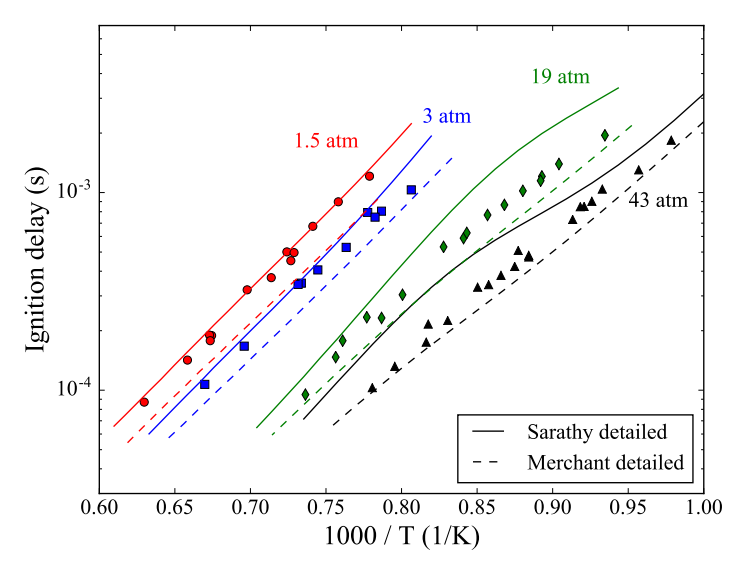

(b) isobutanol

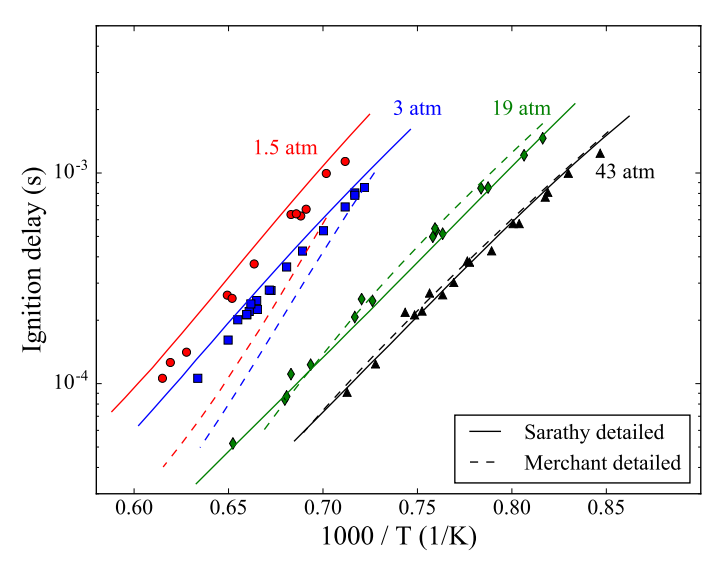

(d) tert-butanol

Figure 2: Comparison of butanol isomer ignition delay times between experiments (symbols) and simulations (lines) using detailed Sarathy and Merchant detailed mechanisms for pressures of 1.5, 3, 19, and $43 \mathrm{~atm}$; a range of temperatures, and equivalence ratios of 0.6-1.0 in mixtures containing $4 \% \mathrm{O}_{2}$ diluted in argon. Experimental data are taken from Stranic et al. $\sqrt[5]{5}$.

Figures 2 and 3 compare the performances of the detailed Sarathy and Merchant mechanisms with experimentally measured ignition delay times ${ }^{5}$ and laminar flame speeds ${ }^{14}$. As seen in Fig. 2, the Sarathy mechanism agrees with ignition delay data for all the isomers 


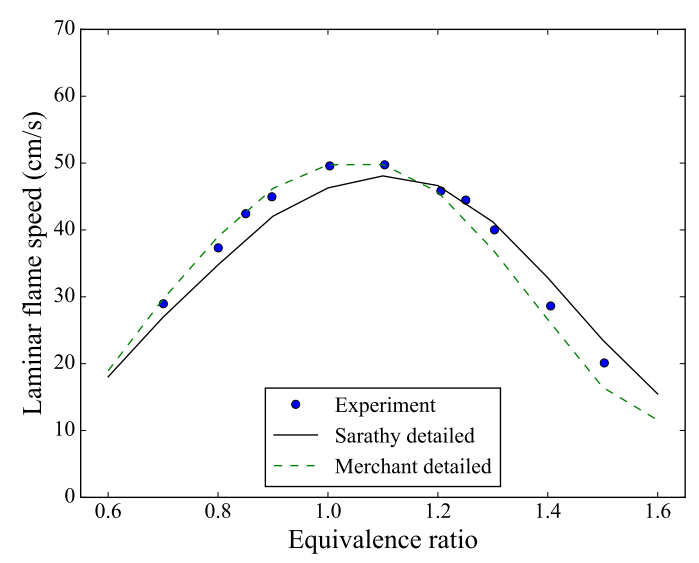

(a) n-butanol

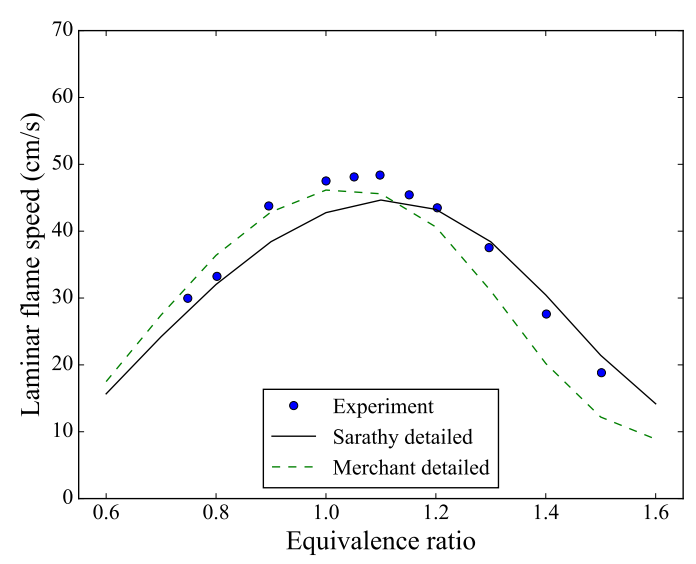

(c) sec-butanol

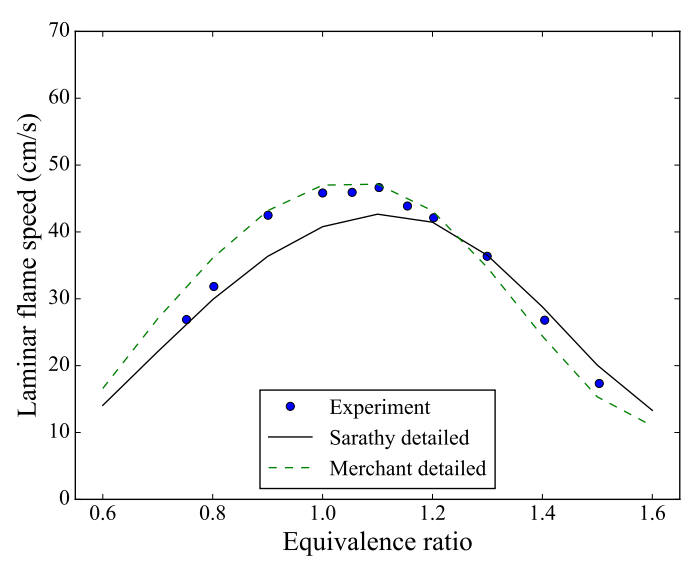

(b) isobutanol

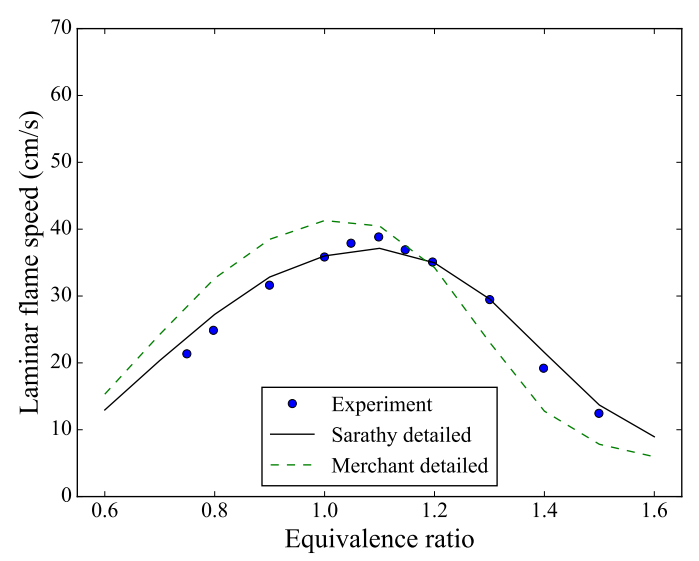

(d) tert-butanol

Figure 3: Comparison of butanol isomer laminar flame speeds between experiments (symbols) and simulations (lines) using detailed Sarathy and Merchant detailed mechanisms for a range of equivalence ratios in air at $1 \mathrm{~atm}$ and an unburned mixture temperature of $434 \mathrm{~K}$. Experimental data are taken from Veloo et al. 14 . 
except for isobutanol at high pressures of 19 and $40 \mathrm{~atm}$, while the Merchant mechanism agrees with most of the experimental data except for sec-butanol at high pressures 19 and $40 \mathrm{~atm}$ and tert-butanol at 1.5 and $3 \mathrm{~atm}$. The laminar flame speed comparison in Fig. 3 shows that both the Sarathy and Merchant mechanisms approximately match the experimental data, though some discrepancies exist between the two mechanisms, including the equivalence ratio location of peak laminar flame speed. The respective original publications provide additional validation against other experimental data for the Sarathy and Merchant mechanisms.

\section{Reduction procedure}

The reduction of the detailed mechanisms was performed at two levels: DRGEP and full DRGEPSA. The first level applies the DRGEP method to quantify the importance of each species to the predetermined target species through a graph-based representation of species interdependence within the reaction system. Species are removed when their importance values fall below a cutoff threshold, which is determined iteratively based on a user-specified error limit. After a skeletal mechanism is generated by DRGEP, greedy sensitivity analysis further removes certain "limbo" species whose overall importance coefficients fall between the cutoff threshold and a specified upper threshold, while remaining within the specified error limit. Additional details of the reduction methodology can be found in the works of Niemeyer and coworkers 44 46154. This study used version 2.3.0 of MARS (Mechanism Automatic Reduction Software) $)^{55}$ to perform the reduction, which added support for the newer logarithmic and Chebyshev pressure-dependent reaction formulations (discussed in more detail later) compared to the version used by Niemeyer and Sung $\underline{46}$.

The reduction procedure used autoignition and PSR simulation data to both generate thermochemical state data (e.g., to calculate DRGEP species interaction coefficients) and to evaluate trial skeletal mechanism performance. The reactants butanol, $\mathrm{O}_{2}$, and $\mathrm{N}_{2}$ were

chosen as the target species in the reduction process, following the practice of Niemeyer and 
coworkers in prior studies using DRGEP 44 46154. Since we are primarily interested in SI or CI engines operating at high temperatures, the reduction validations are limited to temperatures above 1000 K. Specifically, the autoignition simulations cover initial temperatures of 1000$1800 \mathrm{~K}$, pressures of $1-40 \mathrm{~atm}$, and equivalence ratios of $0.5-1.5$. PSR simulations cover the same ranges of pressure and equivalence ratio, with an inlet temperature of $400 \mathrm{~K}$. The error limit level for DRGEP was set to $10 \%$, while the upper threshold value for the SA phase was set to 0.1 . MARS determines the DRGEP cutoff threshold value iteratively based on the $10 \%$ error limit, starting at $1 \times 10^{-3}$ and increasing until it reaches the error limit. Niemeyer and Sung $\frac{45[46}{4}$ suggested using these values to achieve appreciable mechanism reduction without compromising accuracy. MARS evaluates skeletal mechanism error using both ignition delay times and PSR temperatures at three points along the upper branch of the response curve with respect to residence time: the extinction turning point, near a residence time of $0.1 \mathrm{~s}$, and the logarithmic midpoint between the first two points 46 .

Table 1: Summary of results from skeletal reduction of the Sarathy mechanism for butanol isomers, with 284 species and 1892 reactions. $\epsilon_{\mathrm{EP}}$ represents the DRGEP cutoff threshold.

\begin{tabular}{lccccc}
\hline & \multicolumn{2}{c}{ DRGEP } & \multicolumn{2}{c}{ DRGEPSA } \\
& $\epsilon_{\mathrm{EP}}$ & Species & Reactions & Species & Reactions \\
\hline$n$-butanol & $2.3 \times 10^{-2}$ & 86 & 637 & 61 & 409 \\
isobutanol & $2.4 \times 10^{-2}$ & 85 & 574 & 58 & 385 \\
sec-butanol & $1.5 \times 10^{-2}$ & 95 & 687 & 62 & 425 \\
tert-butanol & $2.0 \times 10^{-2}$ & 81 & 536 & 64 & 445 \\
\hline
\end{tabular}

Table 2: Summary of results from skeletal reduction of the Merchant mechanism for butanol isomers, with 372 species and 8322 reactions. $\epsilon_{\mathrm{EP}}$ represents the DRGEP cutoff threshold.

\begin{tabular}{lccccc}
\hline & \multicolumn{2}{c}{ DRGEP } & \multicolumn{2}{c}{ DRGEPSA } \\
& $\epsilon_{\mathrm{EP}}$ & Species & Reactions & Species & Reactions \\
\hline n-butanol & $1.4 \times 10^{-2}$ & 102 & 1904 & 68 & 1046 \\
isobutanol & $2.0 \times 10^{-3}$ & 153 & 3405 & 81 & 1709 \\
sec-butanol & $1.1 \times 10^{-2}$ & 108 & 2197 & 69 & 1357 \\
tert-butanol & $7.0 \times 10^{-3}$ & 117 & 1755 & 78 & 1114 \\
\hline
\end{tabular}

Tables 1 and 2 show the sizes of the resulting skeletal mechanisms for the Sarathy and 
Merchant mechanisms, respectively. The DRGEP method removes most of the unimportant species for all butanol isomers, resulting in skeletal mechanisms less than one third the size of the respective detailed parent, except in the case of isobutanol in the Merchant model, whose skeletal mechanism is $50 \%$ larger than those of the other three isomers. As the Merchant mechanism was recently optimized for isobutanol, it contains more detailed chemical pathways for this isomer. Further application of SA removes an additional 21-36\% of remaining species - except in the case of Merchant isobutanol, where $47 \%$ are removed - to generate the final skeletal mechanisms.

\section{Pressure-dependent reactions}

In addition to the canonical Arrhenius dependence of reaction rates on temperature, the reaction rates of certain reactions are also dependent on pressure. Such reactions include, for example, dissociation reactions, isomerization reactions, radical-radical recombination reactions, and elimination reactions. Pressure dependence is typically expressed as unimolecular/ recombination fall-off reactions and chemically activated bimolecular reactions. In general, the rates of unimolecular/recombination fall-off reactions increase with increasing pressure, while the rates of chemically activated bimolecular reactions decrease with increasing pressure. To capture the "fall-off" behavior of these reactions, their reaction rate coefficients are usually described by modified Arrhenius expressions utilizing low- and high-pressure limit constants and a fall-off factor that smoothly connects the limiting rate coefficients between the fall-off regimes. The Lindemann, Troe, and SRI formulations of Lindemann et al. $\frac{56}{\text {, }}$ Gilbert et al. $\frac{57}{}$, and Stewart et al. $\stackrel{58}{ }$, respectively, provide analytical expressions for the falloff factor and have been quite successful at describing most pressure-dependent reactions.

However, for more complex reactions with multiple energy wells and products, the fall-off behavior cannot be satisfactorily fitted using a single Arrhenius expression. More accurate

formulations based on logarithmic interpolation (i.e., pressure-log) $\sqrt[59160]{ }$ and Chebyshev polynomials $^{59}$ have been proposed and used in more recent chemical kinetic models, such as 
the Sarathy and Merchant mechanisms employed in the present study. Caution needs to be exercised when implementing the pressure-log and Chebyshev reactions due to their complex formulations, and care needs to be taken with regards to their validity range to prevent unjustified extrapolation outside their specified limits. This is particularly true in the case of Chebyshev polynomials, as their formulation is mathematically constrained to the stated pressure and temperature limits. Beyond these general cautions, however, in the process of our mechanism reduction several issues were encountered for certain pressure-log reactions, and we would like to clarify them in the remainder of this section in an effort to motivate a more consistent method of applying such pressure-log reactions in future studies.

In a pressure-log reaction, the reaction rate constant $k_{i}\left(T, P_{i}\right)$ at a specified pressure $P_{i}$ and a temperature $T$ is given by

$$
k_{i}\left(T, P_{i}\right)=A_{i} T^{b_{i}} \exp \left(-E_{i} / R T\right)
$$

where $A_{i}, b_{i}$, and $E_{i}$ are the pre-exponential factor, temperature exponent, and activation energy, respectively, given for a specified pressure $P_{i}$ in a pressure-log reaction. Usually, several rate expressions at different specified pressures will be given to cover a range of pressures. The reaction rate constant $k(T, P)$ at any intermediate pressure $P_{i}<P<P_{i+1}$ can be computed by a log fitting method using $k_{i}\left(T, P_{i}\right)$ and $k_{i+1}\left(T, P_{i+1}\right)$ as given by

$$
\log k(T, P)=\log k_{i}\left(T, P_{i}\right)+\left(\log k_{i+1}\left(T, P_{i+1}\right)-\log k_{i}\left(T, P_{i}\right)\right) \frac{\log P-\log P_{i}}{\log P_{i+1}-\log P_{i}}
$$

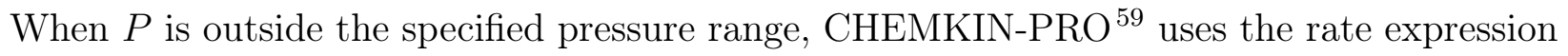
at the limit pressure to avoid an error, although the validity of this approach cannot be justified.

Many mechanisms also allow certain identical reactions to proceed at different rates; these reactions can be defined as "declared duplicate" reactions with separate sets of rate expressions. For pressure-log reactions, such utility can be achieved by using multiple rate 
expressions at the same pressure in one reaction, in which case the rate constants used in Eq. (2) are the sum of all the rate constants given at that pressure. Both methods are commonly used; however, for pressure-log reactions the formulation of duplicate reactions and the formulation of multiple rate expressions are not equivalent, and in fact can yield very different results. We use the decomposition reaction of isobutanol $\left(i \mathrm{BuOH} \longleftrightarrow i \mathrm{C}_{4} \mathrm{H}_{8}+\mathrm{H}_{2} \mathrm{O}\right)$ in the Merchant mechanism to illustrate this behavior. This reaction is originally defined in the form of duplicate reactions in the Merchant mechanism, as shown below in CHEMKIN format (for the sake of brevity the rate expressions at only 10 and 100 atm are shown):

$\begin{array}{llll}\begin{array}{l}\text { iBuOH }=\text { iC4H8 }+\mathrm{H} 2 \mathrm{O} \\ \text { ! Pressure (atm) }\end{array} & \mathrm{A} & \mathrm{b} & \mathrm{E}(\mathrm{cal} / \mathrm{mol}) \\ \text { PLOG 10.0 } & 3.13 \mathrm{E}+51 & -10.82 & 96480 \\ \text { PLOG 100.0 } & 4.24 \mathrm{E}+27 & -4.0 & 80731.98 \\ \text { duplicate } & & & \\ \text { iBuOH = iC4H8 + H2O } & & & \\ \text { ! Pressure (atm) } & \mathrm{A} & \mathrm{b} & \mathrm{E}(\mathrm{cal} / \mathrm{mol}) \\ \text { PLOG 10.0 } & 5.10 \mathrm{E}+16 & -1.46 & 66679.9 \\ \text { PLOG 100.0 } & 5.83 \mathrm{E}+09 & 0.61 & 63570 \\ \text { duplicate } & & & \end{array}$

The above duplicate pressure-log reactions can also be reformulated using multiple rate expressions into a single pressure-log reaction format:

$\begin{array}{llll}\mathrm{iBuOH}=\mathrm{iC} 4 \mathrm{H} 8+\mathrm{H} 2 \mathrm{O} & & & \\ \text { ! Pressure (atm) } & \mathrm{A} & \mathrm{b} & \mathrm{E}(\mathrm{cal} / \mathrm{mol}) \\ \text { PLOG 10.0 } & 3.13 \mathrm{E}+51 & -10.82 & 96480 \\ \text { PLOG 10.0 } & 5.10 \mathrm{E}+16 & -1.46 & 66679.9 \\ \text { PLOG 100.0 } & 4.24 \mathrm{E}+27 & -4.0 & 80731.98 \\ \text { PLOG 100.0 } & 5.83 \mathrm{E}+09 & 0.61 & 63570\end{array}$

Both formulations are syntactically valid, but each will cause isobutanol to decompose into isobutene and water at different rates. Figure 4 compares the half-life times of isobutanol using the duplicate-reaction and multiple-expression formulations at a constant pressure of $40 \mathrm{~atm}$ and temperature of $1000 \mathrm{~K}$, illustrating the differences between the two approaches. The decomposition of isobutanol can proceed at two different rates as represented by the first and second reactions in the duplicate-reaction formulation; however, when combined the duplicate-reaction formulation predicts a slower decay than the multiple-expression formu- 
lation, resulting in half-life times of $47.5 \mathrm{~s}$ and $29.0 \mathrm{~s}$ for the duplicate-reaction and multipleexpression formulations, respectively. This difference occurs because the duplicate-reaction formulation calculates the net rate coefficient as the sum of the logarithmically interpolated rate coefficients, while the multiple-expression formulation sums the rate coefficients prior to interpolation. As long as the difference between these two formulations is understood, the mechanism developer should intentionally choose the proper formulation for a given pressure-log reaction with multiple reaction rates.

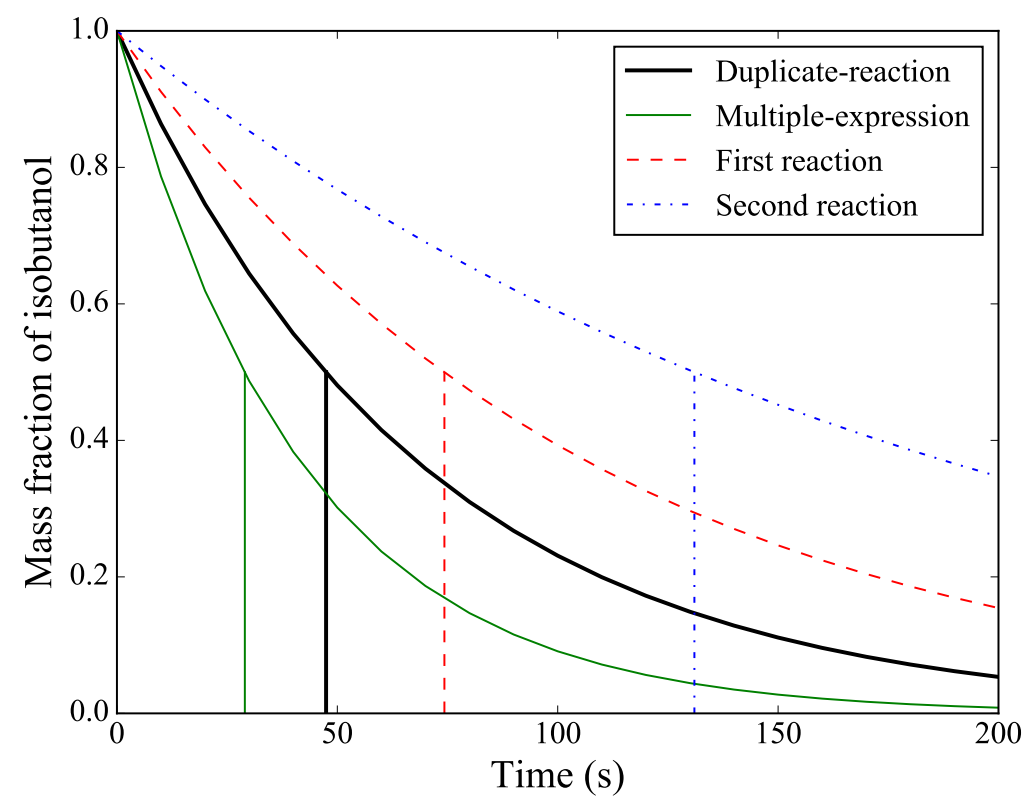

Figure 4: Comparison of half-life times of isobutanol for the reaction $i \mathrm{BuOH} \longleftrightarrow i \mathrm{C}_{4} \mathrm{H}_{8}+$ $\mathrm{H}_{2} \mathrm{O}$ implemented using the duplicate-reaction and multiple-expression pressure-log formulations, at a constant temperature of $1000 \mathrm{~K}$ and pressure of $40 \mathrm{~atm}$. The consumption of isobutanol due to the first and second reactions alone in the duplicate-reaction formulation are also shown for reference.

Another issue can arise with negative pre-exponential factors in pressure-log reactions: duplicate-reaction formulations cannot allow a negative value, since the logarithm of a negative rate coefficient would be undefined. In contrast, the single-reaction, multiple-expression formulation allows a negative pre-exponential factor as long as the sum of the rate constants at the same pressure remains positive. As it turns out, this issue is not hypothetical: in the Merchant mechanism, one isobutanol reaction describing decomposition into a methyl radi- 
cal and 2-hydroxypropyl $\left(i \mathrm{BuOH} \longleftrightarrow \mathrm{CH}_{3}+\mathrm{C}_{3} \mathrm{H}_{7} \mathrm{O}-2\right)$ contains a negative pre-exponential factor in the duplicate pressure-log format, which forces the logarithm of a negative rate constant and thus causes a failure in our mechanism reduction process due to an undefined value. Brady et al. ${ }^{8}$ observed the same problem in their study on forced ignition of the butanol isomers. Perhaps more worryingly, when the same reaction is used in CHEMKIN-PRO ${ }^{59}$, the software proceeds with the calculation without showing any warning or error messages. Cantera, an alternative open-source software $\sqrt{60}$, stops with an error message. Given the nature of the interpolation, it is unclear what allows CHEMKIN-PRO calculations to proceed. In order to facilitate as broad a mechanism comparison as possible, this reaction was removed from the Merchant mechanism before our reduction process. The removal of this isobutanol decomposition reaction is deemed valid for $n-$, sec-, and tert-butanols since it has little effect on their oxidation pathways. As for isobutanol, we assume that the pathway of isobutanol decomposing into methyl and 2-hydroxypropyl is not significant due to its high activation energy $(132,857 \mathrm{cal} / \mathrm{mol})$ compared with other pathways via H-abstract reactions and other decomposition reactions. Calculations of ignition delays and laminar flame speeds without this problematic reaction agree well with experimental data as shown in Figs. 2 and 3, suggesting that its removal does not adversely impact the mechanism performance. Therefore, the reaction of $i \mathrm{BuOH} \longleftrightarrow \mathrm{CH}_{3}+\mathrm{C}_{3} \mathrm{H}_{7} \mathrm{O}-2$ was excluded from the Merchant mechanism in our present study.

\section{Validation of skeletal mechanisms}

We first performed a validation of the skeletal mechanisms in autoignition simulations over a range of initial temperatures, pressures, and equivalence ratios. Figures 5 and 6 show and compare the ignition delay times for the butanol isomers at stoichiometric conditions predicted by detailed and skeletal mechanisms for the Sarathy and Merchant mechanisms, respectively. As the low-temperature chemistry is not considered in this study, the ignition 


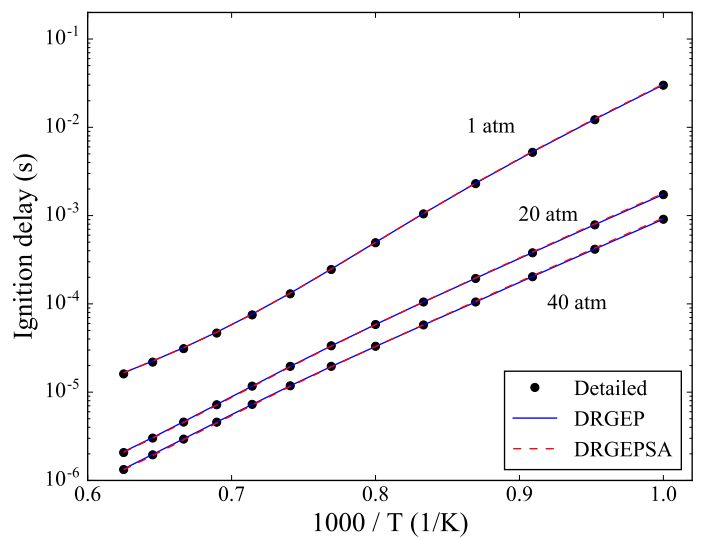

(a) $n$-butanol

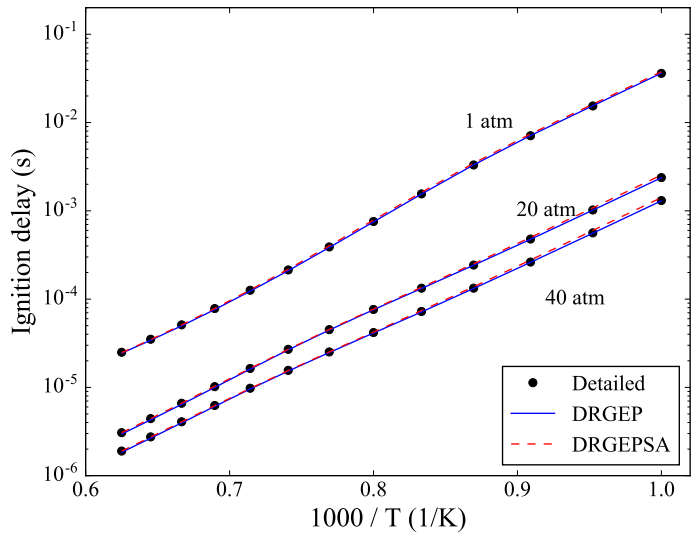

(c) sec-butanol

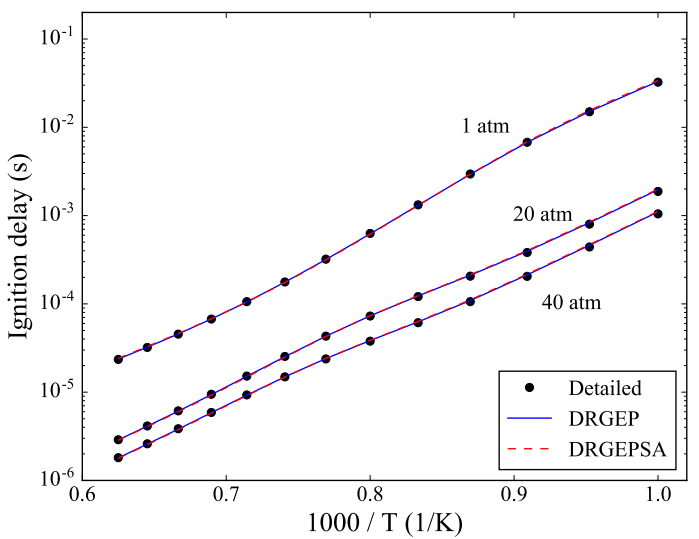

(b) isobutanol

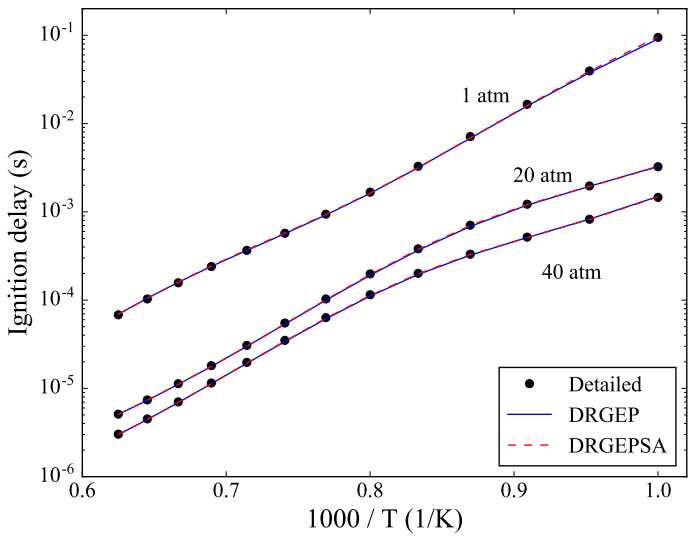

(d) tert-butanol

Figure 5: Ignition delay times of butanol isomers using Sarathy detailed and skeletal DRGEP and DRGEPSA mechanisms for initial temperatures of 1000-1600 K; pressures of 1, 20, and $40 \mathrm{~atm}$; and an equivalence ratio of 1.0 in air. 


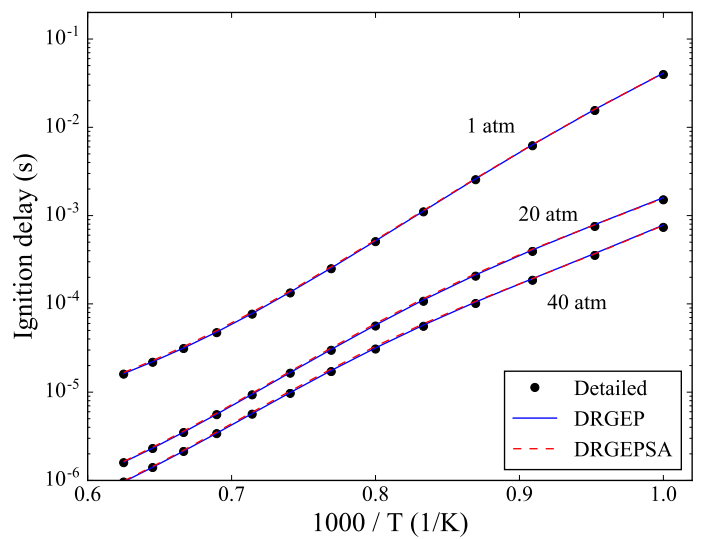

(a) $n$-butanol

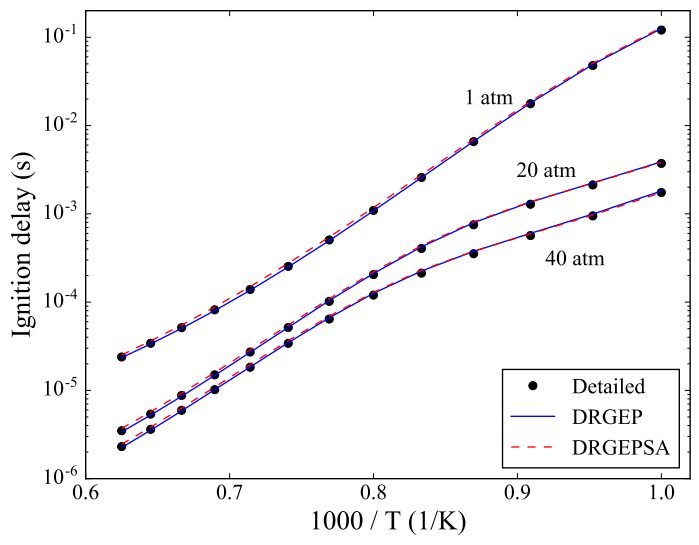

(c) sec-butanol

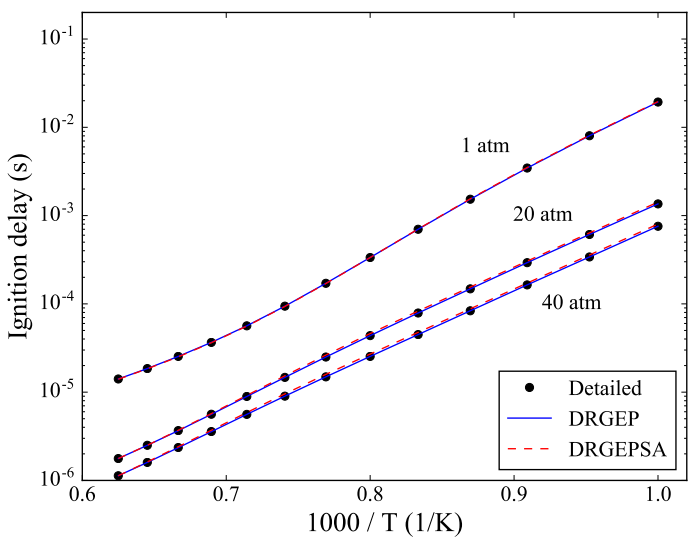

(b) isobutanol

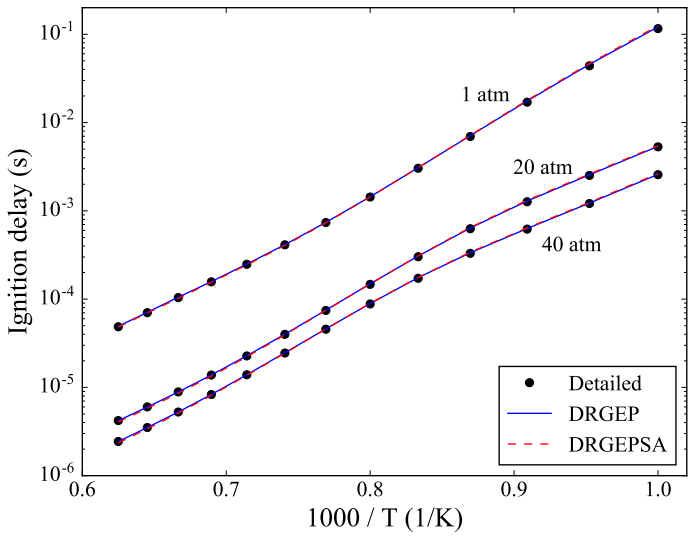

(d) tert-butanol

Figure 6: Ignition delay times of butanol isomers using Merchant detailed and skeletal DRGEP and DRGEPSA mechanisms for initial temperatures of 1000-1600 K; pressures of 1,20 , and $40 \mathrm{~atm}$; and an equivalence ratio of 1.0 in air. 
simulations only consider high-temperature chemistry starting from $1000 \mathrm{~K}$. The results show that both of the DRGEP and DRGEPSA skeletal mechanisms - indicated by the solid and dashed lines, respectively - accurately predict the ignition delay times of the corresponding detailed parent over the validated temperature and pressure ranges. Comparisons of ignition delay predictions at equivalence ratios of 0.5 and 1.5 , though not shown here, demonstrate similar agreement between skeletal and detailed mechanisms for both Sarathy and Merchant mechanisms. Time evolutions of temperature are also compared to further validate the skeletal mechanisms. Figure 7 compares the time evolutions of temperature for $n$-butanol at equivalence ratios of 0.5 and 1.0 to further validate the skeletal mechanisms. For all cases, the temperature profiles are indistinguishable over the entire ignition process. Comparisons for other isomers also show good agreement, suggesting that the ignition kinetics are properly retained through the reduction process.

Next, PSR simulations were used to validate the skeletal mechanisms in extinction phenomena. Figures 8 and 9 show temperature response curves as a function of residence time at equivalence ratios of $0.5,1.0$, and 1.5 and pressures of 1 and $40 \mathrm{~atm}$ for the Sarathy and Merchant mechanisms, respectively. The upper branch of the C-shaped temperature curve represents stable flame solutions, while the lower branch represents unstable flame solutions that are not experimentally accessible. The turning point between the upper and lower branches represents the extinction limit, and the corresponding residence time is called the extinction residence time. The skeletal mechanisms closely capture the temperature profiles predicted by the detailed mechanisms for all the isomers at lean, stoichiometric, and rich conditions, demonstrating the capability of the skeletal mechanisms in predicting the flame limit phenomenon.

Figures 10 and 11 compare the simulated laminar flame speeds obtained by the detailed and skeletal mechanisms at an unburned mixture temperature of $400 \mathrm{~K}$ and pressures of 1 , 20, and $40 \mathrm{~atm}$. The skeletal mechanisms generally closely match the detailed mechanisms for all butanol isomers with the Sarathy and Merchant mechanisms. Average deviations from 


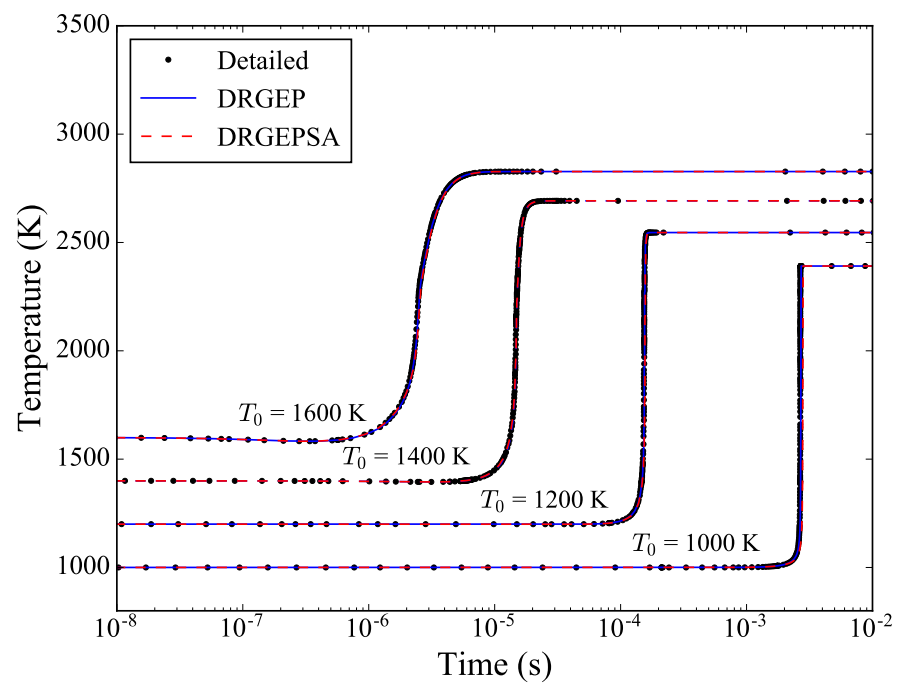

(a) $\phi=0.5$

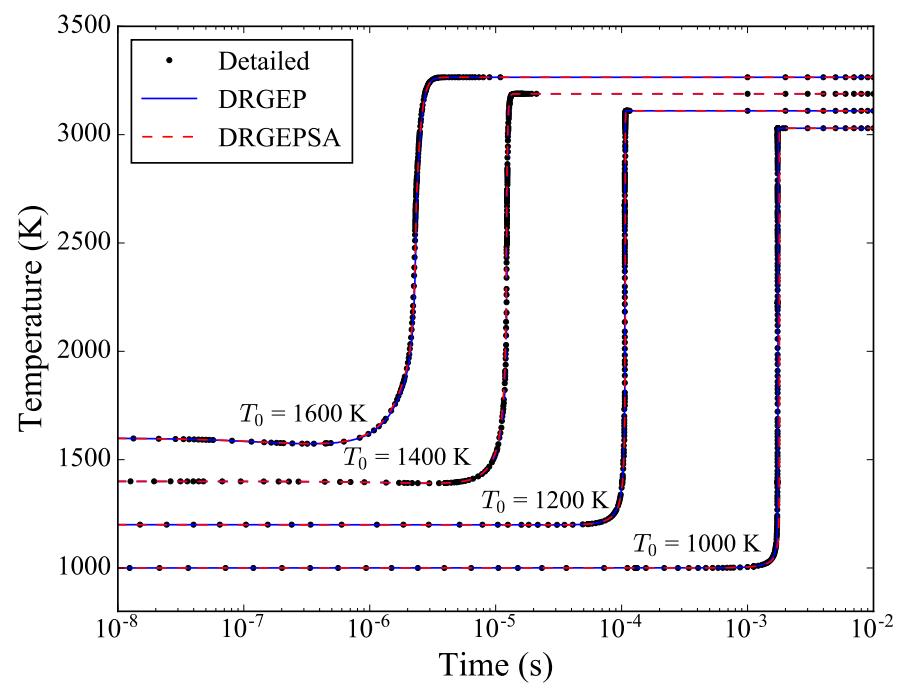

(b) $\phi=1.0$

Figure 7: Comparison of autoignition temperature profiles for $n$-butanol using Sarathy detailed and skeletal mechanisms at initial temperatures of $T_{o}=1000,1200,1400$, and $1600 \mathrm{~K}$; an inlet pressure of $20 \mathrm{~atm}$; and equivalence ratios of 1.0 and 0.5 in air. 


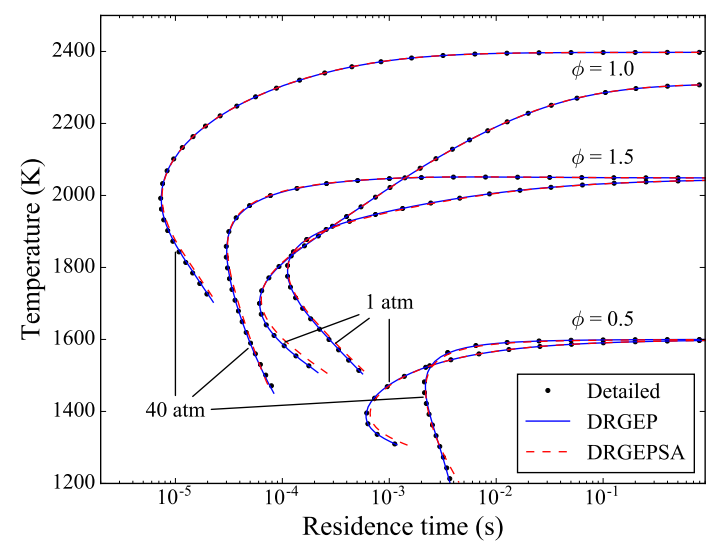

(a) n-butanol

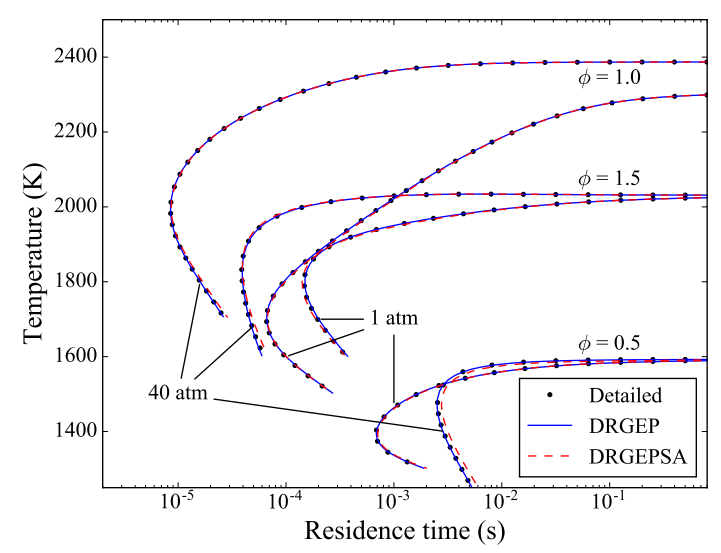

(c) sec-butanol

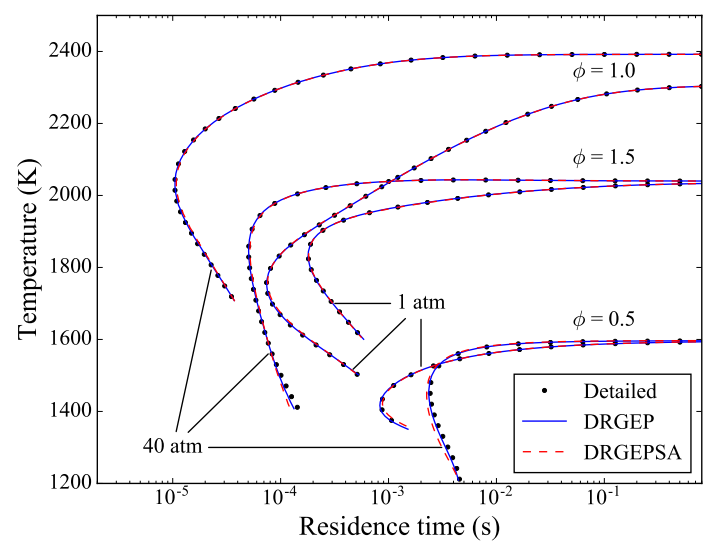

(b) isobutanol

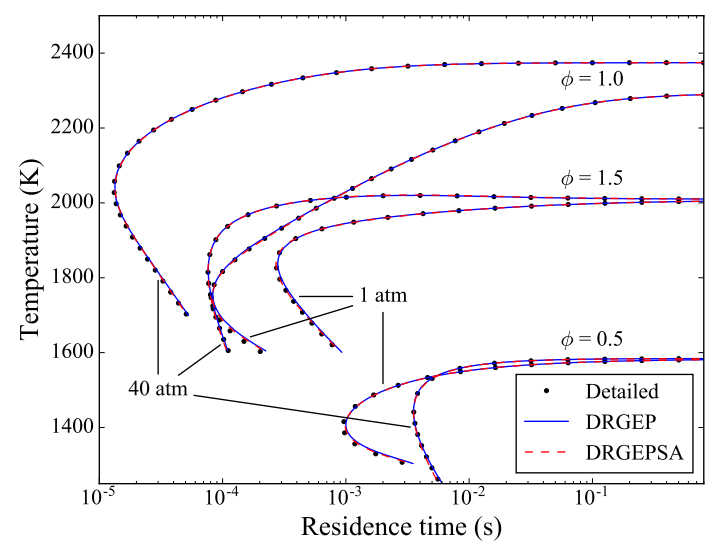

(d) tert-butanol

Figure 8: Comparison of PSR temperature response curves for butanol isomers using Sarathy detailed and skeletal DRGEP and DRGEPSA mechanisms at an inlet temperature of $400 \mathrm{~K}$, equivalence ratio of 1.0 in air, and pressures of 1 and $40 \mathrm{~atm}$. 


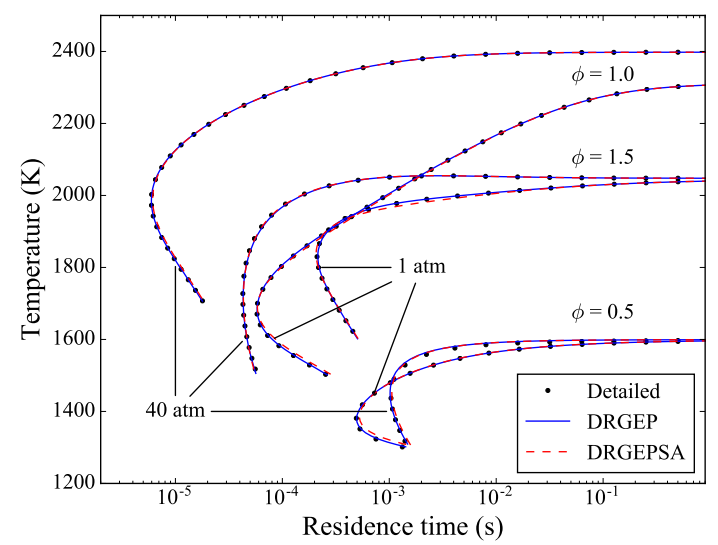

(a) n-butanol

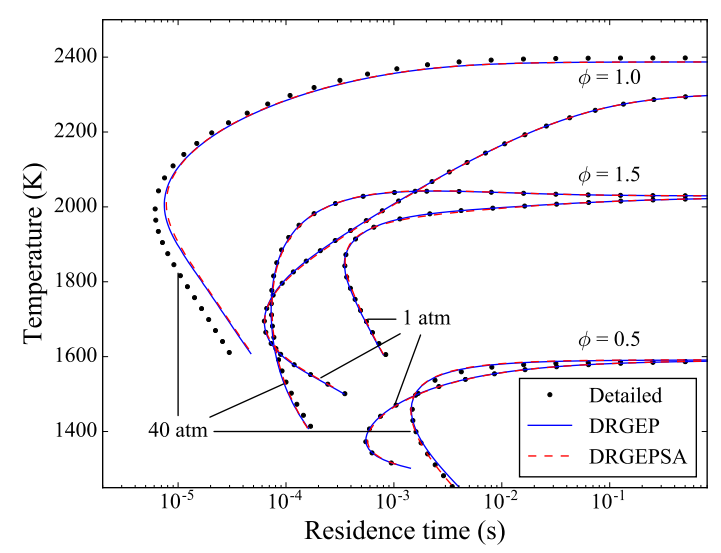

(c) sec-butanol

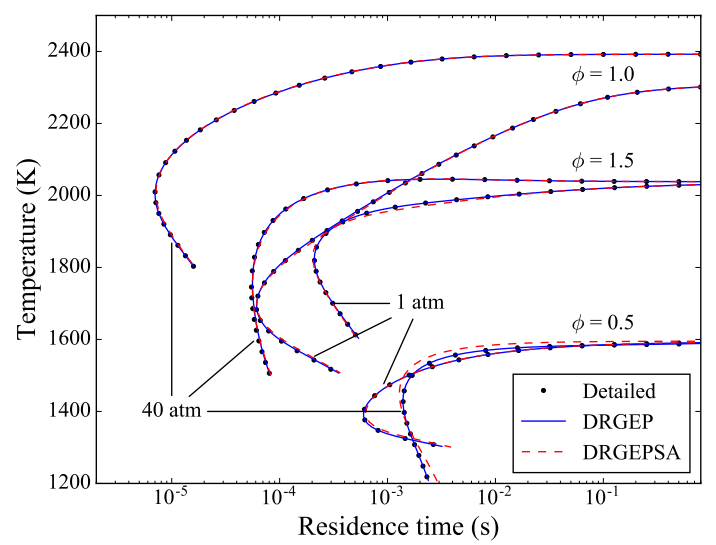

(b) isobutanol

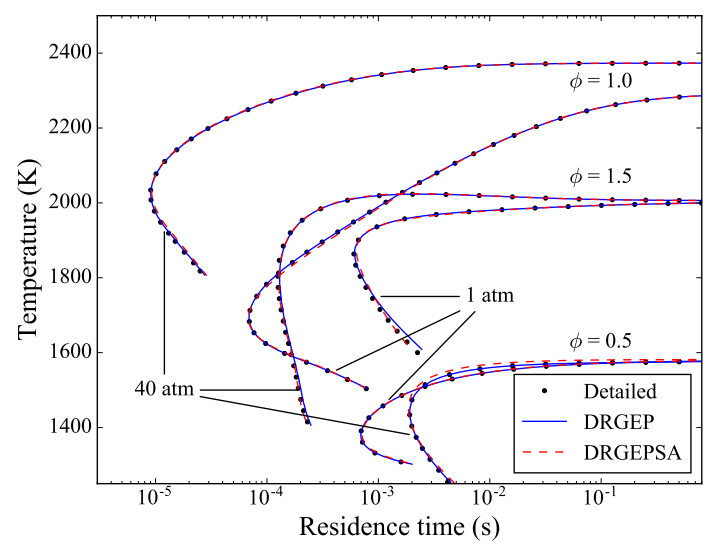

(d) tert-butanol

Figure 9: Comparison of PSR temperature response curves for butanol isomers using Merchant detailed and skeletal DRGEP and DRGEPSA mechanisms at an inlet temperature of $400 \mathrm{~K}$, equivalence ratio of $1.0 \mathrm{in}$ air, and pressures of 1 and $40 \mathrm{~atm}$. 
the detailed parent are $0.88 \%$ and $1.40 \%$ for DRGEP and DRGEPSA skeletal mechanisms of the Sarathy mechanism, respectively, and $1.95 \%$ and $1.99 \%$ for the Merchant mechanism. Calculations with the final DRGEPSA skeletal mechanisms deviate at most $6.4 \%$ for sec-butanol with the Sarathy mechanism and $7.2 \%$ for tert-butanol with the Merchant mechanism, respectively.

For each mechabnism, we also performed sensitivity analyses of laminar flame speed at an unburned mixture temperature of $400 \mathrm{~K}$, pressure of $1 \mathrm{~atm}$, and stoichiometric equivalence ratio. Figure 12 shows the sensitivity of $n$-butanol laminar flame speed with respect to preexponential factors using the Sarathy mechanism. The laminar flame speed is most sensitive to reactions describing $\mathrm{H}_{2} / \mathrm{CO}$ chemistry with chain propagation/termination reactions involving $\mathrm{H}$ and $\mathrm{OH}$ radicals. The skeletal mechanisms at both reduction levels produce similar sensitivities. The close agreements in both laminar flame speed and sensitivities suggests that the skeletal mechanisms retain the dominant flame kinetics and important reactions through the reduction process.

While valuable, matching global combustion properties such as ignition delay times, extinction limits, and flame propagation does not necessarily guarantee fidelity of the skeletal mechanisms when simulating time-evolving combustion processes. Therefore, further validation was performed for HCCI engine simulations by using an internal combustion engine simulator contained within CHEMKIN-PRO 59 . The engine simulation was conducted at an equivalence ratio of 0.5 , initial temperature of $489 \mathrm{~K}$, initial pressure of $1.48 \mathrm{~atm}$, compression ratio of 14 , and an engine speed of $1200 \mathrm{rpm}$. Niemeyer and Sung $\underline{45}$ used the same conditions in a previous study of a gasoline surrogate. Figures 13 and 14 show the mass fractions of butanol isomers as a function of engine crank angle $\left({ }^{\circ} \mathrm{CA}\right)$ simulated by the Sarathy and Merchant mechanisms, respectively. The simulations with the Sarathy- and Merchantbased skeletal mechanisms both agree well with the corresponding parent mechanism, both exhibiting maximum deviations of approximately $0.5^{\circ} \mathrm{CA}$ in the sec-butanol case.

Comparing the four butanol isomers, the Sarathy mechanism predicts that $n$-butanol 


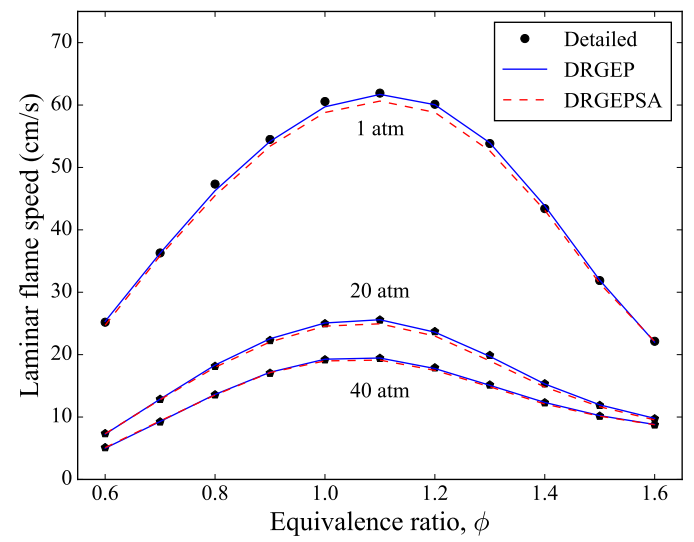

(a) $n$-butanol

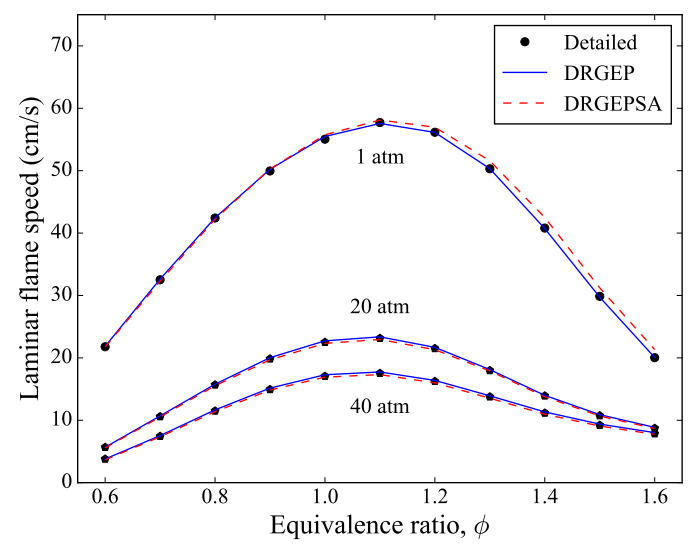

(c) sec-butanol

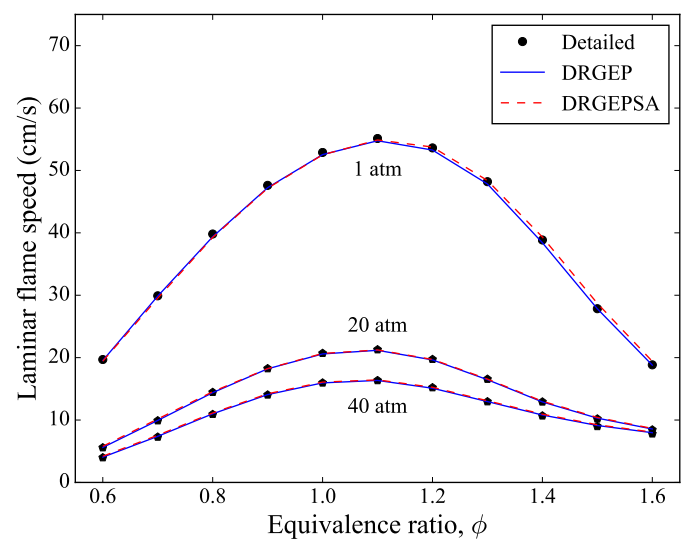

(b) isobutanol

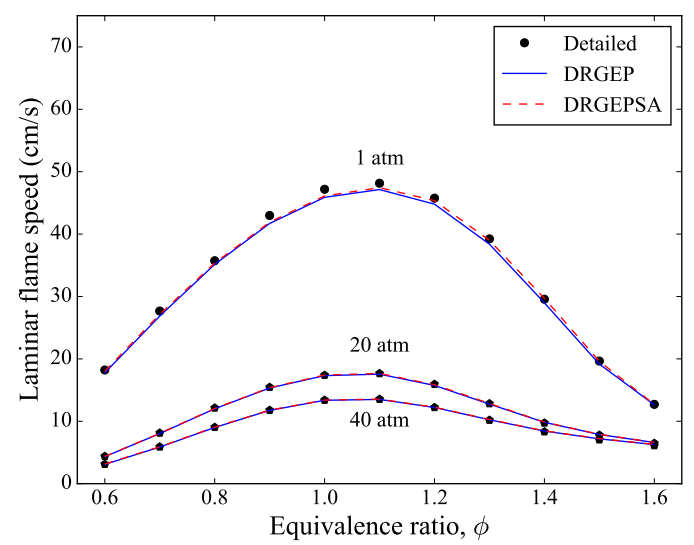

(d) tert-butanol

Figure 10: Comparison of laminar flame speed predictions for butanol isomers as a function of equivalence ratio in air using Sarathy detailed and skeletal DRGEP and DRGEPSA mechanisms at pressures of 1, 20, and $40 \mathrm{~atm}$ and an unburned mixture temperature of $400 \mathrm{~K}$. 


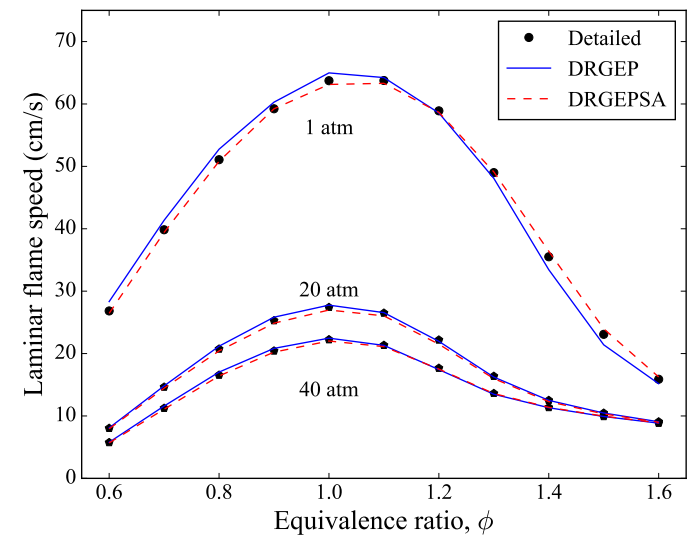

(a) $n$-butanol

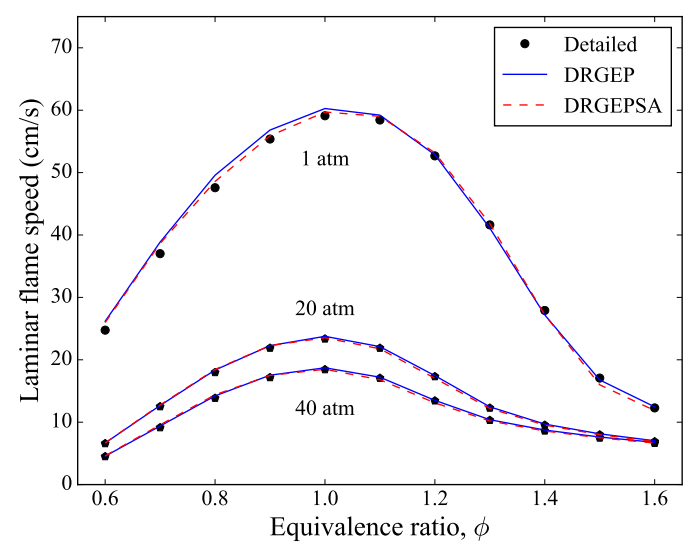

(c) sec-butanol

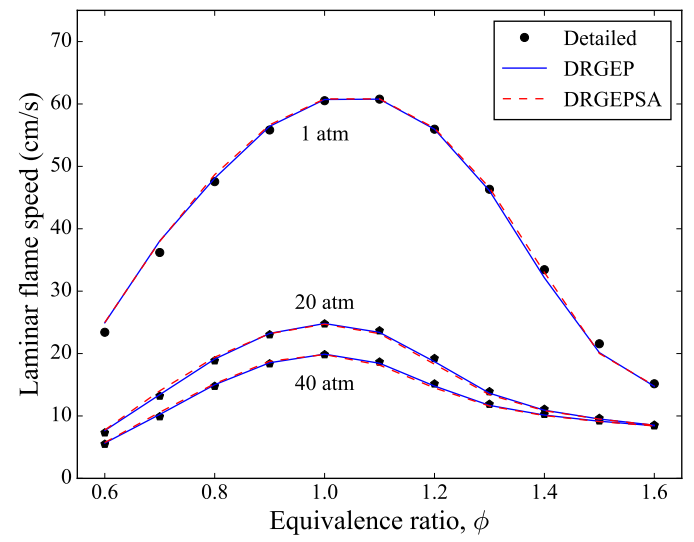

(b) isobutanol

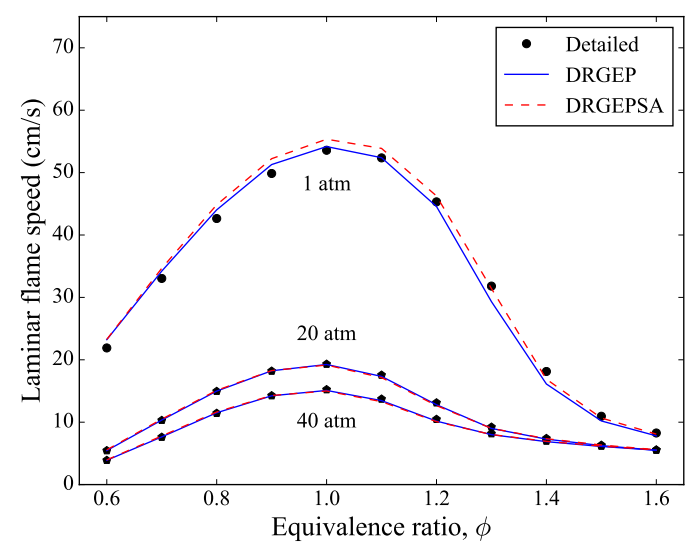

(d) tert-butanol

Figure 11: Comparison of laminar flame speed predictions for butanol isomers as a function of equivalence ratio in air using Merchant detailed and skeletal DRGEP and DRGEPSA mechanisms at pressures of 1,20, and $40 \mathrm{~atm}$ and an unburned mixture temperature of $400 \mathrm{~K}$. 


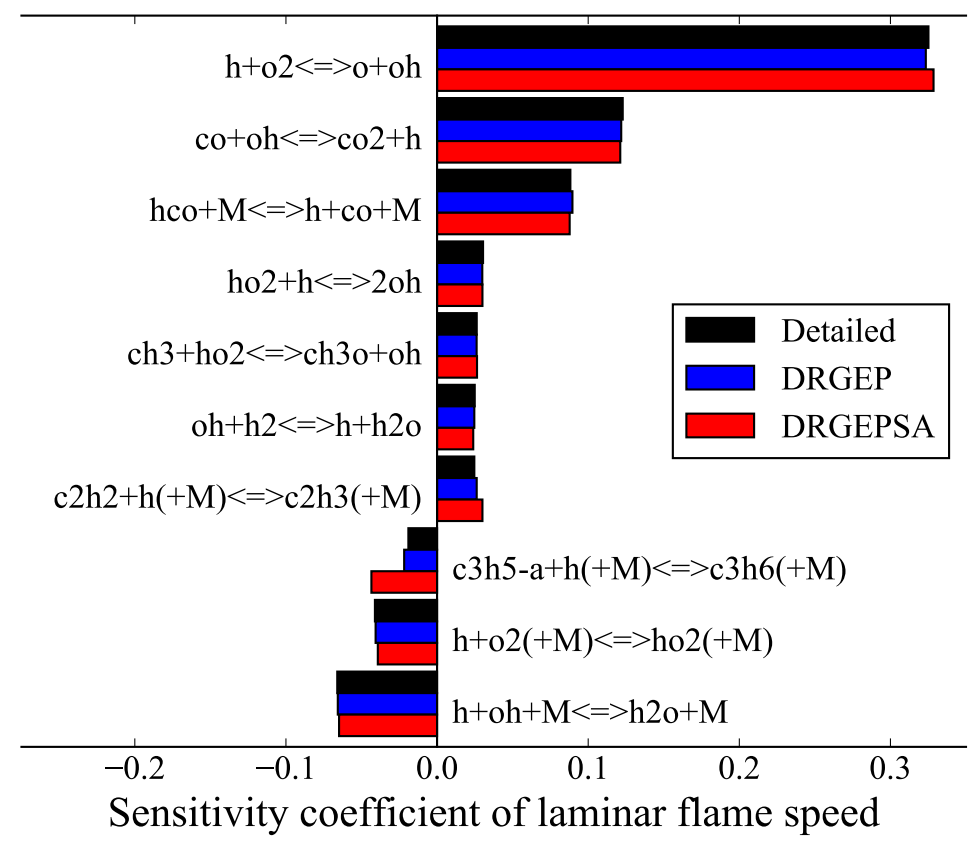

Figure 12: Sensitivity analysis of laminar flame speed for stoichiometric $n$-butanol/air mixture using Sarathy detailed and skeletal DRGEP and DRGEPSA mechanisms at an unburned mixture temperature of $400 \mathrm{~K}$ and pressure of 1 atm.

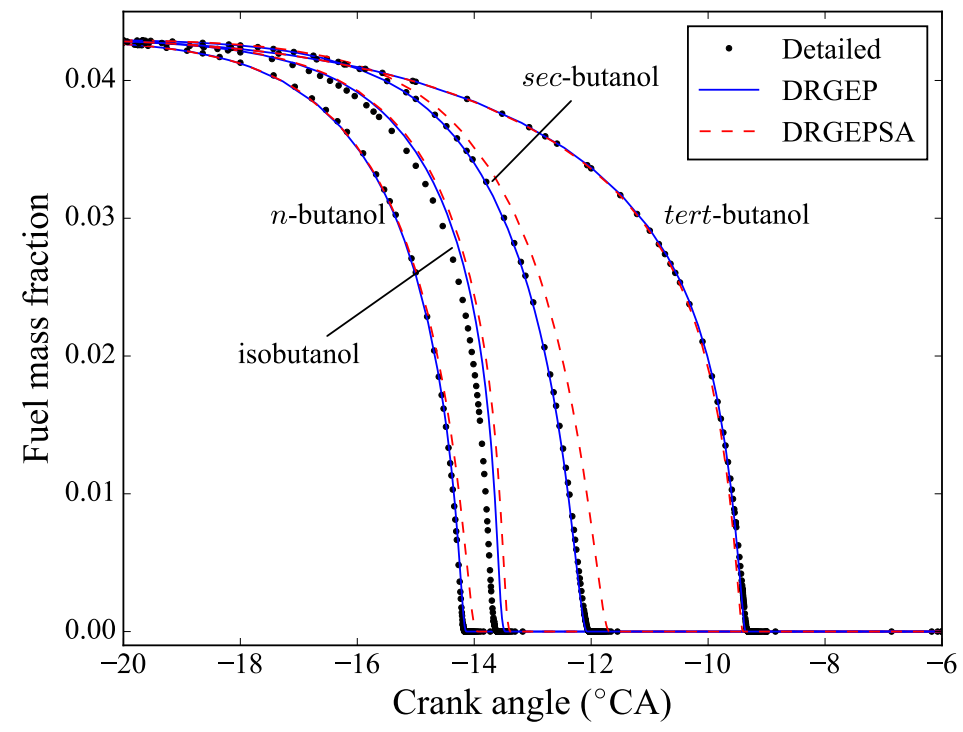

Figure 13: Mass fractions of butanol isomers in engine simulation using Sarathy detailed and skeletal DRGEP and DRGEPSA mechanisms at equivalence ratio of 0.5 in air, initial temperature of $489 \mathrm{~K}$, pressure of $1.48 \mathrm{~atm}$, compression ratio of 14 , and engine speed of $1200 \mathrm{rpm}$. 


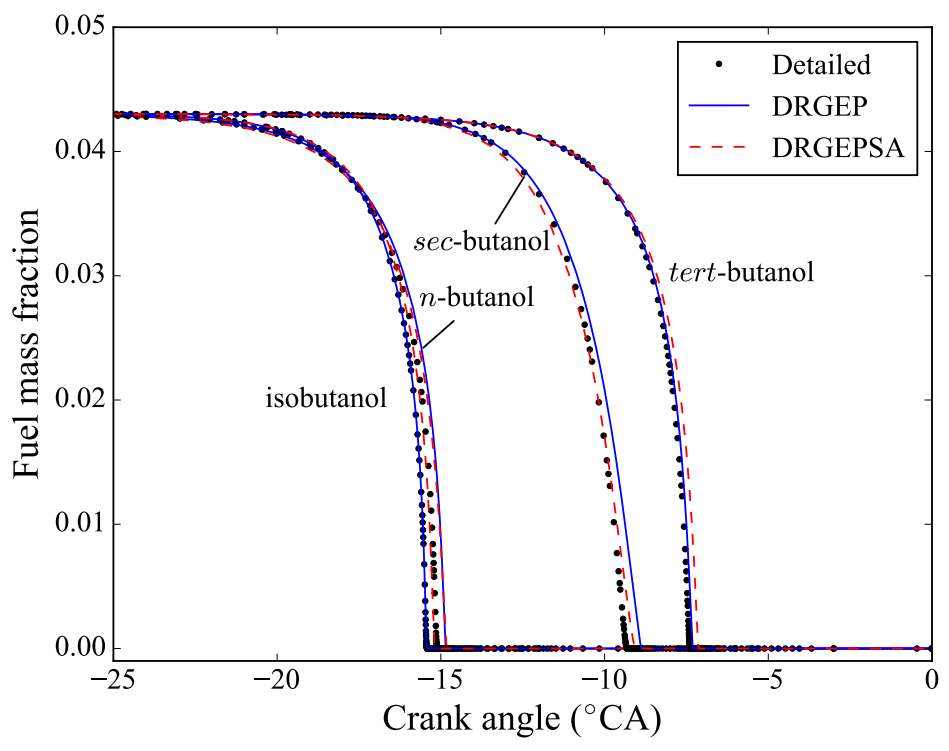

Figure 14: Mass fractions of butanol isomers in engine simulation using Merchant detailed and skeletal DRGEP and DRGEPSA mechanisms at equivalence ratio of 0.5 in air, initial temperature of $489 \mathrm{~K}$, pressure of $1.48 \mathrm{~atm}$, compression ratio of 14 , and engine speed of $1200 \mathrm{rpm}$.

exhibits the fastest consumption rate, and hence the shortest combustion duration (crank angles from $90 \%$ to $10 \%$ of fuel mass fraction), followed by iso, sec-, and tert-butanols. The Merchant mechanism predicts that isobutanol and $n$-butanol have the fastest consumption rates, followed by sec- and tert-butanols. Compared to the other three isomers, the slower consumption rate of tert-butanol predicted by both Sarathy and Merchant mechanisms can be attributed to its high activation energy; tert-butanol's lower reactivity has been demonstrated in several experimental configurations including autoignition delay ${ }^{5 / 7}$, ignition temperature $^{8}$, and laminar flame speed ${ }^{13}$. It is also noted that tert-butanol is currently used as an octane enhancer in gasoline. Comparing the relative behavior of the butanol isomers between the Sarathy and Merchant mechanisms, $n$-butanol exhibits a noticeably faster consumption rate than isobutanol in the Sarathy mechanism, but a somewhat slower consumption rate than isobutanol in the Merchant mechanism. A close comparison of the experimental data on ignition delay and atmospheric laminar flame speed in Figs. 2 and 3. respectively, shows that $n$-butanol manifests faster ignition at near-atmospheric pressures 
and slightly higher laminar flame speeds than isobutanol; at high pressures, ignition delays for $n$-butanol are comparable to those of isobutanol. Previous studies on high temperature ignition delay ${ }^{\sqrt[517]{7}}$ and laminar flame speed ${ }^{[3 \mid 15}$ showed that $n$-butanol has the highest reactivity, followed by iso and sec-butanols, and tert-butanol has the lowest reactivity. Other studies on forced ignition temperature ${ }^{\sqrt[8]{3}}$ and laminar flame speed ${ }^{14}$ showed similar reactivity among $n$-, iso, and sec-butanols, while the reactivity of tert-butanol is consistently lower than the other three isomers.

To compare the engine performance of butanol isomers with that of conventional gasoline, a skeletal mechanism ${ }^{46}$ proposed for a gasoline surrogate ${ }^{63164}$ was used in our engine simulation for the same conditions used in the butanol isomer simulations. This gasoline skeletal mechanism contains 97 species and 512 reactions for a gasoline surrogate consisting of $48.8 \%$ isooctane, $15.3 \% n$-heptane, $30.6 \%$ toluene, and $5.3 \%$ 2-pentene by mole, which has an anti-knock index of 87 and a sensitivity of $8 \underline{64}$. Figures 15 and 16 compare the normalized fuel mass fraction and pressure profiles of the gasoline surrogate with all four butanol isomers simulated by their respective skeletal mechanisms. Both figures show that consumption of the gasoline surrogate initiates appreciably earlier than those of the butanol isomers, as predicted by both Sarathy and Merchant mechanisms. Both mechanisms predict consumption of $n$ - and isobutanol closest to that of gasoline, although in different orders ( $n$-butanol and isobutanol are consumed first for the Sarathy and Merchant mechanism, respectively). Both mechanisms predict earlier consumption of sec-butanol than tert-butanol, with nearly the same difference in consumption times between the two fuels. The pressure profile comparison in Fig. 16 again shows that the gasoline surrogate ignites first, followed by iso and $n$-butanols predicted by the Merchant mechanism, and then $n$-, iso, sec-, and tert-butanols predicted by Sarathy mechanism. The sec-and tert-butanols predicted by the Merchant mechanism ignite last. In general, the observed trend somehow follows the octane rates of the gasoline surrogate ${ }^{64}$ and butanol isomers ${ }^{65 \mid 66}$. Overall, the results from both mechanisms suggest that $n$-butanol and isobutanol more closely match the reactivity of the 
gasoline surrogate, and could thus more easily be combined with or replace gasoline in a compression-ignition engine.

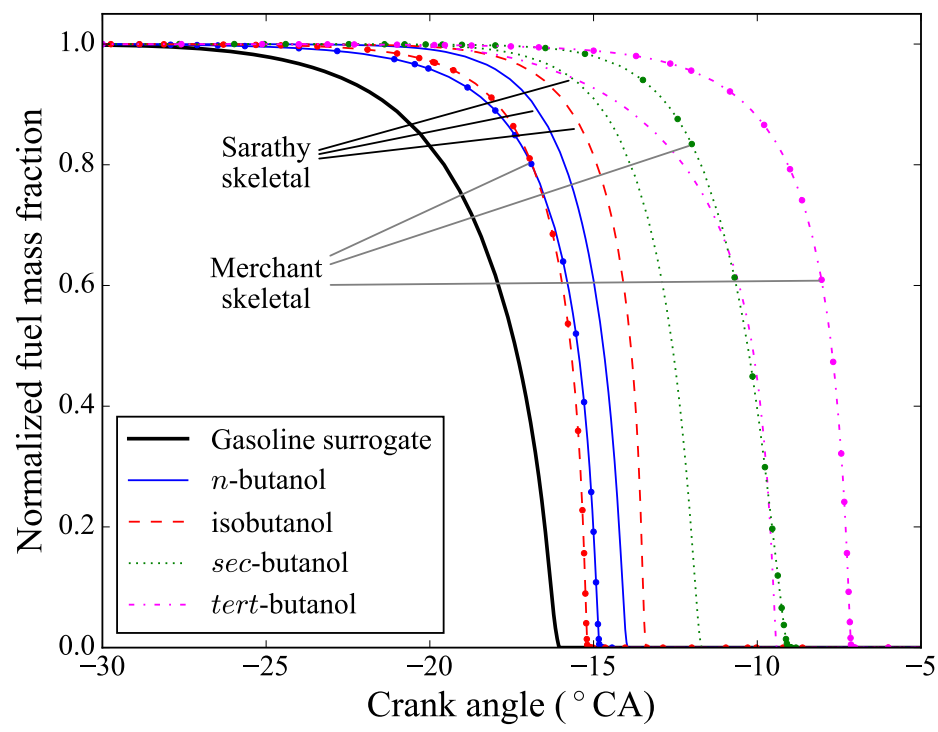

Figure 15: Comparison of normalized fuel mass fraction in engine simulations at equivalence ratio of 0.5 in air, initial temperature of $489 \mathrm{~K}$, pressure of $1.48 \mathrm{~atm}$, compression ratio of 14, and engine speed of $1200 \mathrm{rpm}$. The thick black line indicates gasoline mass fraction and thinner lines indicate butanol isomer mass fractions, with symbols indicating results from the Merchant skeletal mechanisms (and lack of symbols for Sarathy skeletal mechanisms).

\section{Concluding remarks}

In the present study, skeletal mechanisms for each butanol isomer were generated by the DRGEP and DREGPSA reduction methods for the detailed mechanisms of Sarathy and coworkers $^{29 \mid 30}$ and Merchant et al. ${ }^{35}$ The DRGEP method combined with an SA phase removed a significant proportion of the detailed mechanisms while maintaining their essential behaviors, resulting in final DRGEPSA skeletal mechanisms for each isomer ranging from 18$23 \%$ of the size of their parent detailed mechanisms. All of the resulting skeletal mechanisms are limited to high temperature conditions above $1000 \mathrm{~K}$ and pressure up to $40 \mathrm{~atm}$, and cover lean to rich equivalence ratios of $0.5-1.5$. The skeletal mechanisms generated in this study are included as supplemental material with this article. 


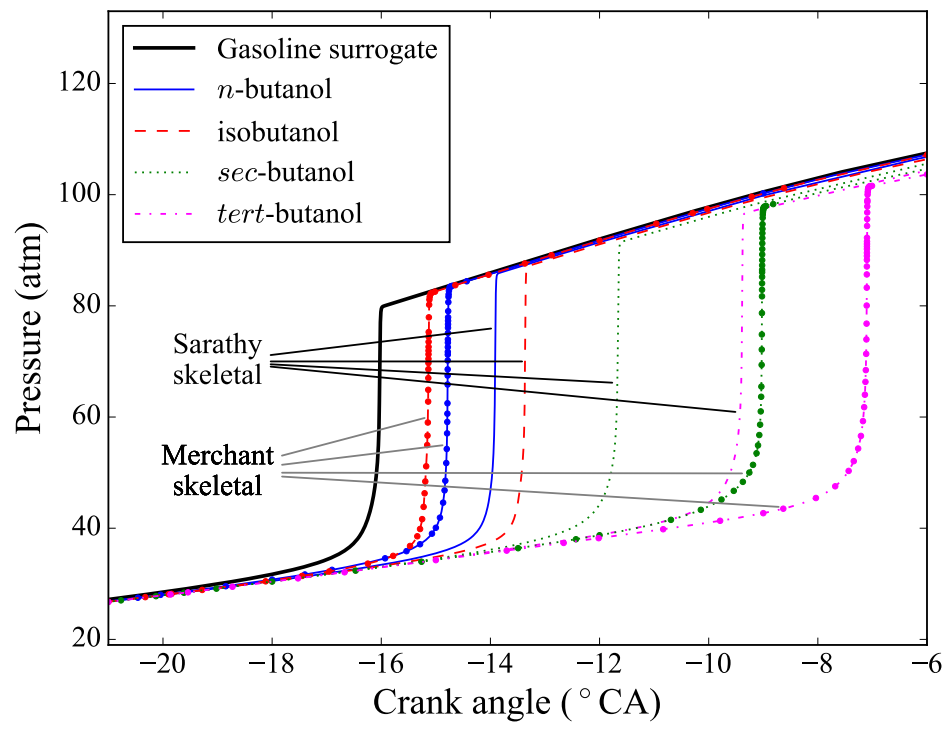

Figure 16: Comparison of pressure profiles in engine simulations at equivalence ratio of 0.5 in air, initial temperature of $489 \mathrm{~K}$, pressure of $1.48 \mathrm{~atm}$, compression ratio of 14 , and engine speed of $1200 \mathrm{rpm}$. The thick black line indicates the gasoline surrogate and thinner lines indicate butanol isomers, with symbols indicating results from Merchant skeletal mechanisms (and lack of symbols for Sarathy skeletal mechanisms).

Validation of the generated skeletal mechanisms demonstrated good matching with the detailed parent mechanisms in terms of ignition delay times, extinction residence times, and laminar flame speeds. Further validation of the skeletal models in HCCI-like engine simulations also showed good agreement. A comparison was also made of engine simulation results for the butanol isomers against a gasoline surrogate of an anti-knock index of 87 at an equivalence ratio of 0.5 in air, inlet temperature of $489 \mathrm{~K}$ and pressure of $1.48 \mathrm{~atm}$, with a compression ratio of 14 and engine speed of $1200 \mathrm{rpm}$. While the gasoline surrogate is consumed faster than all butanol isomers for both skeletal mechanism sets, both sets predict that $n$-butanol and isobutanol are consumed closest to the gasoline (albeit in different orders). tert-Butanol exhibits the slowest consumption rate amongst the four isomers regardless of the parent mechanisms. For the same isomer, the Merchant mechanism predicts faster consumption rates of $n$ - and isobutanol than those predicted by the Sarathy mechanism, while the Sarathy mechanism predicts faster consumption of sec-and tert-butanol than the 
Merchant mechanism. These results indicate that $n$-butanol and isobutanol might be more suitable to supplement or replace gasoline than sec- or tert-butanol.

In addition to the skeletal mechanisms for butanol and comparisons with gasoline produced in this study, issues with pressure-dependent reactions expressed via logarithmic interpolation were also identified and discussed. In particular, the rates of otherwise identical pressure-log reactions exhibit differences when expressed as duplicate reactions or multiple expressions in single reaction. Furthermore, issues can arise with negative pre-exponential Arrhenius factors in such reactions. We therefore recommend that mechanism developers take care in selecting the formulation of pressure-log reactions.

\section{Acknowledgement}

The work at Beihang University was supported by the Project 51306010 of National Natural Science Foundation of China and Project 3152020 of Beijing Natural Science Foundation, while that at the University of Connecticut was supported as part of the Combustion Energy Frontier Research Center, an Energy Frontier Research Center funded by the U.S. Department of Energy, Office of Science, Office of Basic Energy Sciences under Award Number DE-SC0001198

\section{Supporting Information Available}

The following files are available free of charge. The butanol skeletal mechanisms generated from both the Sarathy and Merchant detailed mechanisms are available as supplementary material. The data and plotting scripts used to generate the figures in this paper are also available openly $\underline{67}$. 


\section{References}

(1) Nigam, P. S.; Singh, A. Production of liquid biofuels from renewable resources. Prog. Energy Combust. Sci. 2011, 37, 52-68.

(2) Bergthorson, J. M.; Thomson, M. J. A review of the combustion and emissions properties of advanced transportation biofuels and their impact on existing and future engines. Renewable Sustainable Energy Rev. 2015, 42, 1393-1417.

(3) Heufer, K. A.; Fernandes, R. X.; Olivier, H.; Beeckmann, J.; Röhl, O.; Peters, N. Shock tube investigations of ignition delays of $n$-butanol at elevated pressures between 770 and 1250 K. Proc. Combust. Inst. 2011, 33, 359-366.

(4) Weber, B. W.; Kumar, K.; Zhang, Y.; Sung, C. J. Autoignition of $n$-butanol at elevated pressure and low-to-intermediate temperature. Combust. Flame 2011, 158, 809-819.

(5) Stranic, I.; Chase, D. P.; Harmon, J. T.; Yang, S.; Davidson, D. F.; Hanson, R. K. Shock tube measurements of ignition delay times for the butanol isomers. Combust. Flame 2012, 159, 516-527.

(6) Weber, B. W.; Sung, C. J. Comparative autoignition trends in butanol isomers at elevated pressure. Energy Fuels 2013, 2\%, 1688-1698.

(7) Moss, J. T.; Berkowitz, A. M.; Oehlschlaeger, M. A.; Biet, J.; Warth, V.; Glaude, P.-A.; Battin-Leclerc, F. An experimental and kinetic modeling study of the oxidation of the four isomers of butanol. J. Phys. Chem. A 2008, 112, 10843-10855.

(8) Brady, K. B.; Hui, X.; Sung, C. J. Comparative study of the counterflow forced ignition of the butanol isomers at atmospheric and elevated pressures. Combust. Flame 2016, $165,34-49$.

(9) Brady, K. B.; Hui, X.; Sung, C. J.; Niemeyer, K. E. Counterflow ignition of n-butanol at atmospheric and elevated pressures. Combust. Flame 2015, 162, 3596-3611. 
(10) Liu, W.; Kelly, A. P.; Law, C. K. Non-premixed ignition, laminar flame propagation, and mechanism reduction of n-butanol, iso-butanol, and methyl butanoate. Proc. Combust. Inst. 2011, 33, 995-1002.

(11) Sarathy, S. M.; Thomson, M. J.; Togbe, C.; Dagaut, P.; Halter, F.; MounaïmRousselle, C. An experimental and kinetic modeling study of $n$-butanol combustion. Combust. Flame 2009, 156, 852-864.

(12) Broustail, G.; Seers, P.; Halter, F.; Moréac, G.; Mounaïm-Rousselle, C. Experimental determination of laminar burning velocity for butanol and ethanol iso-octane blends. Fuel 2011, 90, 1-6.

(13) Gu, X.; Huang, Z.; Wu, S.; Li, Q. Laminar burning velocities and flame instabilities of butanol isomers-air mixtures. Combust. Flame 2010, 157, 2318-2325.

(14) Veloo, P. S.; Egolfopoulos, F. N. Flame propagation of butanol isomers/air mixtures. Proc. Combust. Inst. 2011, 33, 987-993.

(15) Wu, F.; Law, C. K. An experimental and mechanistic study on the laminar flame speed, Markstein length and flame chemistry of the butanol isomers. Combust. Flame 2013, $160,2744-2756$.

(16) Agathou, M. S.; Kyritsis, D. C. Experimental investigation of bio-butanol laminar nonpremixed flamelets. Appl. Energy 2012, 93, 296-304.

(17) Lefkowitz, J. K.; Heyne, J. S.; Won, S. H.; Dooley, S.; Kim, H. H.; Haas, F. M.; Jahangirian, S.; Dryer, F. L.; Ju, Y. A chemical kinetic study of tertiary-butanol in a flow reactor and a counterflow diffusion flame. Combust. Flame 2012, 159, 968-978.

(18) Sarathy, S. M.; Oßwald, P.; Hansen, N.; Kohse-Höinghaus, K. Alcohol combustion chemistry. Prog. Energy Combust. Sci. 2014, 44, 40-102. 
(19) No, S.-Y. Application of biobutanol in advanced CI engines - A review. Fuel 2016, 183, 641-658.

(20) Szwaja, S.; Naber, J. D. Combustion of $n$-butanol in a spark-ignition IC engine. Fuel 2010, 89, 1573-1582.

(21) Gu, X.; Huang, Z.; Cai, J.; Gong, J.; Wu, X.; Lee, C.-f. Emission characteristics of a spark-ignition engine fuelled with gasoline- $n$-butanol blends in combination with EGR. Fuel 2012, 93, 611-617.

(22) Al Hasan, M. I.; Al Momany, M. The effect of iso-butanol-diesel blends on engine performance. Transport 2008, 23, 306-310.

(23) Yao, M.; Wang, H.; Zheng, Z.; Yue, Y. Experimental study of n-butanol additive and multi-injection on HD diesel engine performance and emissions. Fuel 2010, 89, 21912201.

(24) Rakopoulos, D. C.; Rakopoulos, C. D.; Papagiannakis, R. G.; Kyritsis, D. C. Combustion heat release analysis of ethanol or $n$-butanol diesel fuel blends in heavy-duty DI diesel engine. Fuel 2011, 90, 1855-1867.

(25) Saisirirat, P.; Togbe, C.; Togbe, C.; Chanchaona, S.; Foucher, F.; Foucher, F.; Mounaim-Rousselle, C.; Mounaïm-Rousselle, C.; Dagaut, P.; Dagaut, P. Auto-ignition and combustion characteristics in HCCI and JSR using 1-butanol $/ n$-heptane and ethanol/n-heptane blends. Proc. Combust. Inst. 2011, 33, 3007-3014.

(26) He, B.-Q.; Liu, M.-B.; Yuan, J.; Zhao, H. Combustion and emission characteristics of a HCCI engine fuelled with n-butanol-gasoline blends. Fuel 2013, 108, 668-674.

(27) He, B.-Q.; Yuan, J.; Liu, M.-B.; Zhao, H. Combustion and emission characteristics of a $n$-butanol HCCI engine. Fuel 2014, 115, 758-764. 
(28) Dagaut, P.; Sarathy, S. M.; Thomson, M. J. A chemical kinetic study of $n$-butanol oxidation at elevated pressure in a jet stirred reactor. Proc. Combust. Inst. 2009, 32, 229-237.

(29) Sarathy, S. M.; Sarathy, S. M.; Vranckx, S.; Yasunaga, K.; Mehl, M.; Oßwald, P.; Metcalfe, W. K.; Westbrook, C. K.; Pitz, W. J.; Kohse-Höinghaus, K.; Fernandes, R. X.; Curran, H. J. A comprehensive chemical kinetic combustion model for the four butanol isomers. Combust. Flame 2012, 159, 2028-2055.

(30) Vasu, S. S.; Sarathy, S. M. On the high-temperature combustion of $n$-butanol: shock tube data and an improved kinetic model. Energy Fuels 2013, 27, 7072-7080.

(31) Rosado-Reyes, C. M.; Tsang, W. Shock Tube Study on the Thermal Decomposition of n-Butanol. J. Phys. Chem. A 2012, 116, 9825-9831.

(32) Frassoldati, A.; Grana, R.; Faravelli, T.; Ranzi, E.; Oßwald, P.; Kohse-Höinghaus, K. Detailed kinetic modeling of the combustion of the four butanol isomers in premixed low-pressure flames. Combust. Flame 2012, 159, 2295-2311.

(33) Grana, R.; Frassoldati, A.; Faravelli, T.; Niemann, U.; Ranzi, E.; Seiser, R.; Cattolica, R.; Seshadri, K. An experimental and kinetic modeling study of combustion of isomers of butanol. Combust. Flame 2010, 157, 2137-2154.

(34) Van Geem, K. M.; Pyl, S. P.; Marin, G. B.; Harper, M. R.; Green, W. H. Accurate High-Temperature Reaction Networks for Alternative Fuels: Butanol Isomers. Ind. Eng. Chem. Res. 2010, 49, 10399-10420.

(35) Merchant, S. S.; Zanoelo, E. F.; Speth, R. L.; Harper, M. R.; Van Geem, K. M.; Green, W. H. Combustion and pyrolysis of iso-butanol: Experimental and chemical kinetic modeling study. Combust. Flame 2013, 160, 1907-1929. 
(36) Lu, T.; Law, C. K. Toward accommodating realistic fuel chemistry in large-scale computations. Prog. Energy Combust. Sci. 2009, 35, 192-215.

(37) Turányi, T.; Tomlin, A. S. Analysis of Kinetic Reaction Mechanisms; Springer-Verlag: Berlin Heidelberg, 2014.

(38) Lu, T.; Law, C. K. A directed relation graph method for mechanism reduction. Proc. Combust. Inst. 2005, 30, 1333-1341.

(39) Lu, T.; Law, C. K. Linear time reduction of large kinetic mechanisms with directed relation graph: $n$-heptane and iso-octane. Combust. Flame 2006, 144, 24-36.

(40) Lu, T.; Law, C. K. On the applicability of directed relation graphs to the reduction of reaction mechanisms. Combust. Flame 2006, 146, 472-483.

(41) Lu, T.; Law, C. K. Strategies for mechanism reduction for large hydrocarbons: $n$ heptane. Combust. Flame 2008, 154, 153-163.

(42) Bendtsen, A.; Glarborg, P.; Dam-Johansen, K. Visualization methods in analysis of detailed chemical kinetics modelling. Comput. Chem. 2001, 25, 161-170.

(43) Pepiot-Desjardins, P.; Pitsch, H. An efficient error-propagation-based reduction method for large chemical kinetic mechanisms. Combust. Flame 2008, 154, 67-81.

(44) Niemeyer, K. E.; Sung, C. J.; Raju, M. P. Skeletal mechanism generation for surrogate fuels using directed relation graph with error propagation and sensitivity analysis. Combust. Flame 2010, 157, 1760-1770.

(45) Niemeyer, K. E.; Sung, C. J. Mechanism reduction for multicomponent surrogates: A case study using toluene reference fuels. Combust. Flame 2014, 161, 2752-2764.

(46) Niemeyer, K. E.; Sung, C. J. Reduced chemistry for a gasoline surrogate valid at enginerelevant conditions. Energy Fuels 2015, 29, 1172-1185. 
(47) Sun, W.; Chen, Z.; Gou, X.; Ju, Y. A path flux analysis method for the reduction of detailed chemical kinetic mechanisms. Combust. Flame 2010, 157, 1298-1307.

(48) Bodenstein, M. Eine Theorie der photomechnischen reaktionsgeschwindigkeit. Z. Phys. Chem. 1913, 85, 329-397.

(49) Chapman, D.; Underhill, L. LV.-The interaction of chlorine and hydrogen. The influence of mass. J. Chem. Soc. Trans. 1913, 103, 496-508.

(50) Lam, S.-H.; Goussis, D. A. Understanding complex chemical kinetics with computational singular perturbation. Symp. (Int.) Combust. 1988, 22, 931-941.

(51) Lam, S.-H. Using CSP to understand complex chemical kinetics. Combust. Sci. Technol. 1993, 89, 375-404.

(52) Lam, S.-H.; Goussis, D. A. The CSP Method for Simplying Kinetics. Int. J. Chem. Kinet. 1994, 26, 461-486.

(53) Lu, T.; Ju, Y.; Law, C. K. Complex CSP for chemistry reduction and analysis. Combust. Flame 2001, 126, 1445-1455.

(54) Niemeyer, K. E.; Sung, C. J. On the importance of graph search algorithms for DRGEPbased mechanism reduction methods. Combust. Flame 2011, 158, 1439-1443.

(55) Niemeyer, K. E. MARS v2.3.0. https://niemeyer-research-group.github.io/ MARS/, 2016.

(56) Lindemann, F.; Arrhenius, S.; Langmuir, I.; Dhar, N.; Perrin, J.; Lewis, W. M. Discussion on "the radiation theory of chemical action". Trans. Faraday Soc. 1922, 17, $598-606$.

(57) Gilbert, R.; Luther, K.; Troe, J. Theory of thermal unimolecular reactions in the fall-off range. II. Weak Collision Rate Constants. Ber. Bunsen Ges. Phys. Chem. 1983, 87, $169-177$. 
(58) Stewart, P.; Larson, C.; Golden, D. Pressure and temperature dependence of reactions proceeding via a bound complex. 2. Application to $2 \mathrm{CH}_{3} \rightarrow \mathrm{C}_{2} \mathrm{H}_{5}+$ H. Combust. Flame 1989, 75, 25-31.

(59) Reaction Design: San Diego, CHEMKIN-PRO 15113. 2012.

(60) Goodwin, D. G.; Moffat, H. K.; Speth, R. L. Cantera: An object-oriented software toolkit for chemical kinetics, Thermodynamics, and Transport Processes. http://www. cantera.org, 2016; Version 2.2.1.

(61) Venkatesh, P. K.; Chang, A. Y.; Dean, A. M.; Cohen, M. H.; Carr, R. W. Parameterization of pressure-and temperature-dependent kinetics in multiple well reactions. AIChE J. 1997, 43, 1331-1340.

(62) Venkatesh, P. K. Damped pseudospectral functional forms of the falloff behavior of unimolecular reactions. J. Phys. Chem. A 2000, 104, 280-287.

(63) Mehl, M.; Pitz, W. J.; Westbrook, C. K.; Curran, H. J. Kinetic modeling of gasoline surrogate components and mixtures under engine conditions. Proc. Combust. Inst. 2011, 33, 193-200.

(64) Mehl, M.; Chen, J.-Y.; Pitz, W. J.; Sarathy, S. M.; Westbrook, C. K. An approach for formulating surrogates for gasoline with application toward a reduced surrogate mechanism for CFD engine modeling. Energy Fuels 2011, 25, 5215-5223.

(65) Yanowitz, J.; Christensen, E.; McCormick, R. L. Utilization of renewable oxygenates as gasoline blending components. Technical Report NREL/TP-5400-50791, 2011; https : //dx.doi.org/10.2172/1024518.

(66) Christensen, E.; Yanowitz, J.; Ratcliff, M.; McCormick, R. L. Renewable oxygenate blending effects on gasoline properties. Energy Fuels 2011, 25, 4723-4733. 
(67) Hui, X.; Niemeyer, K. E.; Brady, K. B.; Sung, C.-J. Data and plotting scripts for "Reduced chemistry for butanol isomers at engine-relevant conditions". figshare, 2016; https://dx.doi.org/10.6084/m9.figshare.3505799. 